Portland State University

PDXScholar

11-8-1977

\title{
Lebendiger Klang der Natura Herders Begriff des "Primitiven" in der Literatur
}

Judy A. Lorenz

Portland State University

Follow this and additional works at: https://pdxscholar.library.pdx.edu/open_access_etds

Part of the German Language and Literature Commons, and the Philosophy Commons Let us know how access to this document benefits you.

\section{Recommended Citation}

Lorenz, Judy A., "Lebendiger Klang der Natura Herders Begriff des "Primitiven" in der Literatur" (1977). Dissertations and Theses. Paper 2605.

https://doi.org/10.15760/etd.2600

This Thesis is brought to you for free and open access. It has been accepted for inclusion in Dissertations and Theses by an authorized administrator of PDXScholar. Please contact us if we can make this document more accessible: pdxscholar@pdx.edu. 
AN ABSTRACT OF THE THESIS OF Judy A. Lorenz for the Master of Arts in German presented November 8, 1977.

Titleı Lebendiger Klang der Natur: Herders Begriff des "Primitiven" in der Iiteratur.

APPROVID BY MEMBERS OF THE THESIS COMMITTEE,

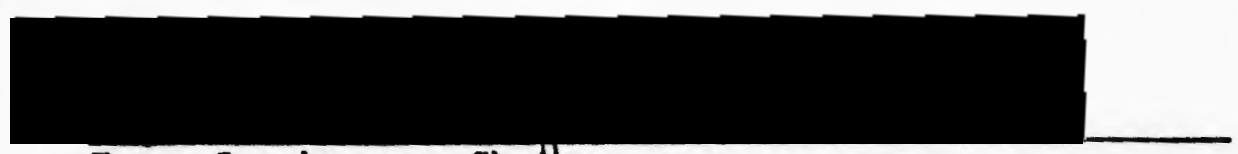

Franz Langhammer, Chathman

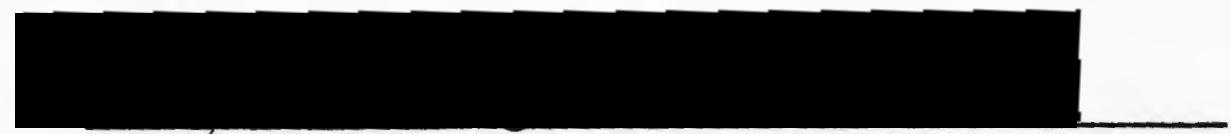

Eugene F. Schnelder

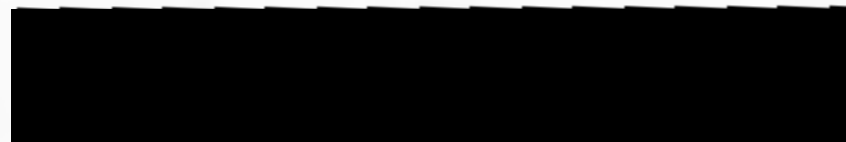

Inda B. Parshall

Johann Gottfried Herder, ein Vorromantiker, fuhrte eine neue Bewegung, eine Volksbewegung, in Deutschland ein. Herder Interesslerte sich fur die Sprache im Allgemeinen und insbesondere fur die "primitiven" Elemente in der deutschen Sprache, die am besten in Volkslledern erscheinen. Seine Bedeutung liegt in der Umwertune des Wortes "primitiv" durch seine Sammlung von nationalen und internationalen Volksliedern.

Wegen der Aufkllirung und deren Betonung von Vernunft und Verstand behauptet Herder, die deutsche Literatur sel zu seiner Zelt elne geist- 
2

lose und geregelte Masse von Worten, die keinen Sinn mehr hatten. Wegen der Nachahmung und Übersetzung der Franzosen, Englander und Griechen konnten die Deutschen nie ihre eigene, originale Literatur schaffen. Wegen der vielen fremden Sprachen in Deutschland verschwand eine Zeitlang der wahre Volkscharakter.

Herder ruft den Deutschen zu, ihren elgenen Volkscharakter wieder durch ihre eigene Muttersprache zu entdecken. Die Muttersprache 1st am besten durch Volkslieder aufbewahrt. Herder betont die Hauptelgenschaften solcher Ileder als "primitiv", lebendig, klangvoll, kraftvoll, original, bildilch, spontan und furs Hbren bestimmt. Dort in den eigenen Liedern des Volkes, Insbesondere des deutschen Volkes, liegt die Basis fur eine echte deutsche Iiteratur. 


\section{IEBENDIGER KLANG DER NATUR:}

HERDERS BECRIFF DES "PRIMITIVEN" IN DER IITERATUR

by

JUDY A. LORENZ

A thesis submitted in partial fulfillment of the requirements for the degree of

\section{MASTER OF ARTS}

in

GERMAN 
TO THE OTFICE OF GRADUATE STUDIES AND RESEARCH \&

The members of the Commlttee approve the thesis of

Judy A. Iorenz presented November 8, 1977.

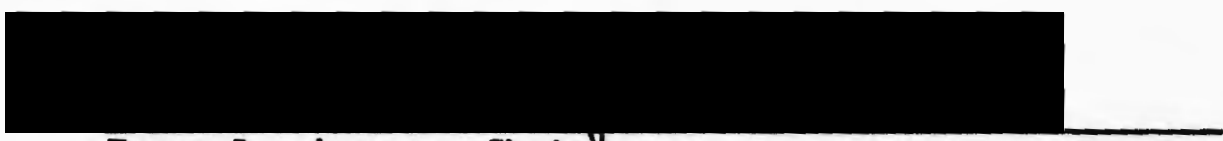

Franz Langhammer, Chairthan

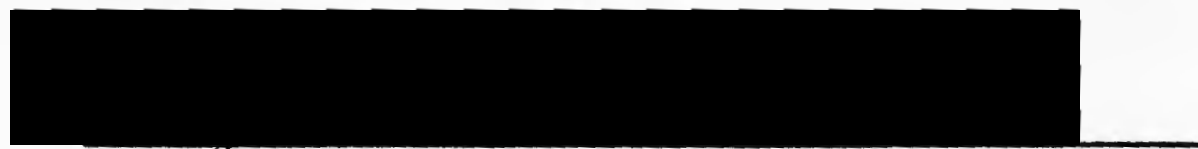

Eugene F. Schneider

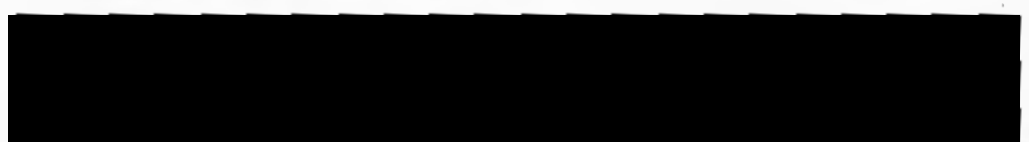

Linda B. Parshall

APPROVED:

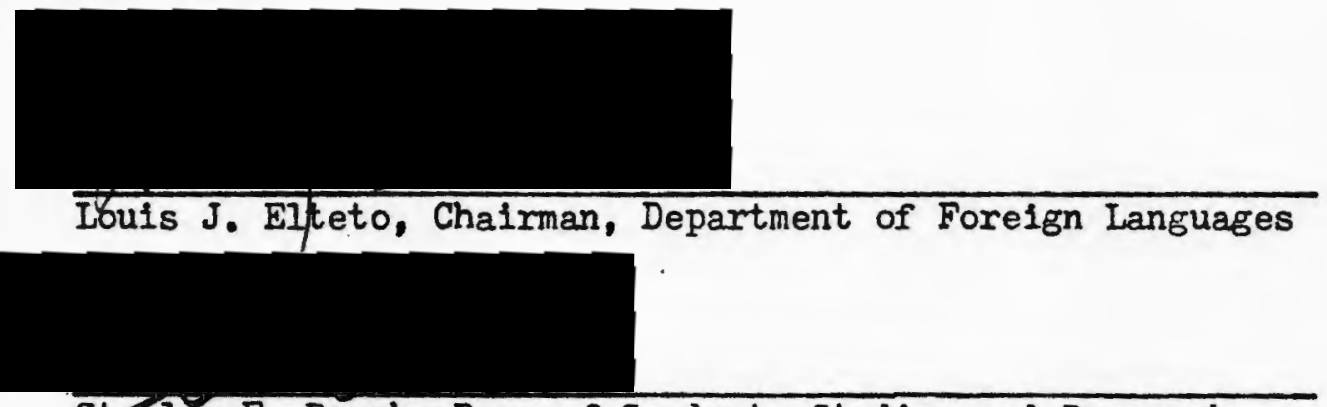

Strify E. Rauch, Dean of Graduate Studies and Research 
DAS INHALTSVERZEICHNIS

SEITE

KAPITEL

I EINATHRUNG ......................

II "KCANG" UND "STIMME" \& VERGIEICH VON ZWEI "PRIMITIVEN" ELEMENTEN ...................

Ursprung der Sprache ..............

Wie "Klang der Natur" mit "Stimme eines Menschen" zu verglelchen ist.........

Übersicht Uber das "Primitive" in wilden Sprachen ......................

III "NATUR" UND "VOLK" VERGLEICH VON ZWEI ANDEREN

"PRIMITIVEN" ELEMENTEN . . . . . . . . . . .

Herders Lebensalter der Sprache . . . . .

Sprache als Basis einer nattrichen Einheit von Menschen ................

Herders Ansichten uber das "Primitive" in der Muttersprache ...............

IV HINDERNISSE IN DER ENTWICKLUNG EINER "PRIMITIVEN"

SPRACHE UND DICHTUNG IN DEUTSCHLAND

Fremde Sprachen .................

Nachahmung, Übersetzung, Regeln ........

$\checkmark$ VERBESSERUNG DER DICHTUNG DURCH DAS "PRIMITIVE"

IN DER SPRACHE ..................

Gebrauch der Muttersprache . . . . .....

Nachahmung "unsrer selbst" . . . . . . . .

41

Die groBen Muster ............... 
KAPITEI

SEITE

Umwertung des Begriffs "Volk" ... . . . . 44 Abschaffung der Regeln der AufkIarung .... . 47

Schreiben als eine Art Sprechen ........ 48

Das Lied als Universalmittel ......... 50

Sammeln von lebendigen Volksliedern . . . . 58

VI SCHLUBFOLGERUNG .................. 61 BIBLIOGRAPHIE . . . . . . . . . . . . . . . . . 71 
KAPITEL I

\section{EINDThIRUNG}

Johann Gottfried Herder wurde im Jahre 1744 in dem ostpreupischen Dorf Mohrungen geboren. Als er achtzehn Jahre alt wurde, ging er nach Konigsberg, um Theologle zu studieren. Zwel Jahre spater wurde er als Hilfslehrer an die Domschule in Riga berufen, wo er auch eine Fredigerstelle bekam. Funf Jahre spater, 1769, verlieB er Riga und machte eine Seereise nach Nantes. Hreiste noch ein paar Jahre durch Frankreich und Deutschland und traf zu dieser zeit in Darmstadt seine zuklinftige Frau, Caroline Flachsland, und knlpfte eine Freundschaft m1t Goethe in StraBburg an. 1771 ging er als Konsistorialrat nach Bllckeburg, wo er funf Jahre wohnte. Von 1776 bis zu selnem Tode 1803, war er Generalsuperintendent in Welmar. Obwohl diese kurzgefaBte Bibliographle nicht besonders bemerkenswert zu sein scheint, war Herders EinfluB auf seine Nachfolger, wie Goethe, Brentano, Eichendorff, Mbrike, thland und andere, sehr groB. An seiner Persbnlichkelt und an seinem leben fullt nichts Besonderes auf. Selne Ideen waren aber tief in seinen Schriften ausgeprkgt. Es waren gerade diese Schriften, In denen seine Ideen "Ieben" bekamen, die Munner und literarlsche Bewegungen des neunzehnten Jahrhunderts beelnfluBten und selbst fur den modernen Menschen des zwanzigsten Jahrhunderts noch Bedeutung haben.

Rudolf Haym, der tber die spatere romantische Schule schrleb, sagte von Herder:

Der Erste, der den Boden fur elne reine, durch keine vorgefaB- 
te Meinung gehemmte Theilnahme an dem Elgenthtimlichen unserer HIteren Nationalpoesie lockerte, war der Mann, der selnen beweglichen Blick bberhaupt Uber die mannigfaltigen Blidungen und Wendungen des Menschlichen hinschwelfen $11 \mathrm{eB}$ und die Regeln insbesondere der Dichtung in der Natur der dichtenden volker, Zeiten, und individuen finden lehrte. 1

Hier sind ein pear wichtige Stichworter zu finden, die die Hauptideen Herders charakterisleren, welche dann elnen neuen Weg ins neunzehnte Jahrhundert vorbere1ten. Diese Horte sind "beweglich", "Dichtung", und "Natur". Man kann sle unschrelben als "Iobendiger Klang der Natur". Diese drel Worte beschrelben die Hauptideen In Herders Schriften aus den Jahren von 1764, als er anfing zu schreiben, bis 1778-1779, als seine zwel Blnde der Volkslieder erschienen, welche spHter den Iitel Stimmen der Volker in Iledern erhielten. Belde Begriffe, "Lebendiger KIang der Natux" und "Stimmen der volker in Liedern", sind miteinander zu vergleichen. Inden dle "Natur" spricht, hat sle elnen "Klang", das heiBt, sle lst "lebendig". Indem dle "VBlker" sprechen, haben sie "Stimmen", die in Ihren "Iledern" immer welter fortleben. Herders Ideen Uber die Sprache von 1764 bis 1779 können hauptsalchlich mit den zwel obenerwahnten Begriffen, den Vergleich zwischen thnen und auch mit den VerhuItnissen zwischen "Klang" und "Stimne". "Natur" und "Volk", und "Iebendif" und "Lleder" verstanden werden. Bs lst deshalb sehr hilfrelch, dlese Worte zu verglelchen. Aber seine Sprachphilosophle kann scharfer elngestellt werden. Alle drel Vergleiche kommen auf das Wort "Sprache" zurlck und vereinigen sich in diesem Wort. DaB die Sprache Herders Hauptbegriff war, Ist schon von anderen erwthnt worden. Carlo Antonl schrelbt:

Die beiden Pole, zwischen denen von Anfang bis zum Ende sein Denken slch bewegte, die Nation und die Humanitut, waren belde wesentlich Sprache, und die Sprache war auch das mittlere Glied, dank dem ex in gewisser Finsicht diese beiden Extremen vereinte.? 
H. A. Korff sagt: "Die Sprache bildet von vornhereln den zentralen Gegenstand von Herders Nachdenken. "3 Robert Rrgang schreibt: "Second to none as a spiritual force in his time, he alded materially in ensconcing German as the Itterary language of Germany, as the language of the classroom and, In general, as the foundation of German culture. " 4 Herder selbst sagte: "Nlemand 1st mehr als 1ch fur die Sprachphilosophle begabt.".5 Herder interessierte sich aber nicht nur fur die Sprache in Allgemeinen, sondern insbesondere fur das "Primitive" in der Sprache, welches er in der Klang form der Sprache entdeckte. Dieses "primitive" Element in der Klangform der gesprochenen Sprache ist das vereinigende Prinzip Herders Ideen. Solches Element kann man am besten in einem Volkslied erkennen, Deswegen folgen drel Volkslieder, dle das "Primitive" in der (gesprochenen) Klangform der Sprache kennzelchnen. Eines Ist ein "primitives" Lied der Wilden, eln anderes eln "primitives" Lled aus dem gemeinen Volke, und das dritte ein "primitives" Lied eines groBen, bekannten DIchters. Z1tate aus diesen Lledern laufen durch die ganze Arbelt hindurch und werden dem Leser Grundbeisplele geben, was Herder mit dem Wort "primitiv" meint. Was 1st also das Kruftige, Muchtige und Wirkungsvolle in diesen drel Lledern? Was meint Herder mit dem Wort "primitiv"? Wle verbindet man nicht nur "Stimme" mit "Klang", "Natur" mit "Volk", "lebendig" mit "Iled", sondern auch alle drel mit dem "Primitiven" In der Klangform der Sprache mit Rucksicht auf diese drel Lieder?

"Die unmenschliche Mutter"

Dieses ist eln Lied der Madagasker und elne Übersetzung aus dem 
Franzosischen des Ritter Parny. Diese Leute wohnen auf elner Insel, auf

der jeder kleine Furst gegen einen anderen klmpft, un Gefangene zu be-

kommen, die er wieder an die Europter verkauft. 6

Elne Mutter schleppte ihre elnzige Tochter ans Ufer, um sle den WeiBeŕ zu verkaufen.

"O meine Mutter: Dein SchoB hat mich getragen, ich bin die erste Frucht delner Ilebe, was habe lch gethan, un die Sklaverel zu verdienen? Ich habe dir deln Alter erlelchtert, habe fll dich das Feld gebaut, flur dich Frllchte gebrochen, flir dich die Fische des Flusses verfolgt, habe dich vor der KHIte bewahrt, In der Hitze dich unter duftende Schatten getragen, bel dis gewacht, wenn du schllefst, und dle Insekten von delnem Gesichte gescheucht. 0 meine Mutter, was wirst du ohne mich werden: Das Geld, welches du fur mich bekomist, wrd dir keine andre Tochter geben. Im Dlende wirst du umkommen, und mein grbBter Schmerz wird sein, daB ich dir nicht helfen kann. 0 meine Mutter, verkaufe delne elnzige Tochter nicht:"

Fruchtlose Bitten: Sle ward verkauft, mit Ketten belastet auf das Schiff gefthrt, und verlieb auf immer ihr theures, sllbes Var terland. 7

\section{"Annchen von Tharau"}

Herder schreibt in Bezug auf dieses Iled aus dem Volke: "Es hat sehr verloren, daB Ichs aus selnem treuherzigen, starken, natven Volksdialekt (aus dem preuBischen Plattdeutsch) Ins Ilebe Hochdeutsch habe verpflanzen mutssen." 8

Annchen von Tharau ist, die mir gefHIIt, Sle ist mein Leben, mein Gut und mein Geld.

Annchen von Tharau hat wieder ihr Herz Auf mich gerichtet in Ileb und in Schmerz.

Annchen von Tharau, mein Reichtum, mein Gut, Du meine Seele, mein Fleisch und mein Blut:

KMn' alles Wetter glelch auf uns $2 u$ schlahn, WIr sind gesinnt beleinander zu stahn.

Krankheit, Verfolgung, Betrlibnis und Pein Soll unsrer Ilebe Verknotigung sein:

Recht als ein Palmenbaum tber sich stelgt, 
Je mehx Ihn Hagel und Regen anficht,

So wird die Lieb in uns machtig und $\mathrm{grOB}$

Durch Krouz, durch Lelden, durch allerlel Not.

Wurdest du gleich einmal von mir getrennt,

Lebtest, da wo man die Sonne kaum kennt,

Ich will dir folgen durch walder, durch Meer,

Durch E1s, durch E1sen, durch felndliches Heer.

Annchen von Tharau, meln Licht, melne Sonn,

Mein Leben schlleB' ich un deines herum.

Was ich geblete, wird von dir getan,

Was ich verblete, das laBt du mir stahn.

Was hat die Ilebe doch fur eln Bestand,

Wo nicht ein Herz 1st, ein Mund, eine Hand?

Wo man sich peiniget, zanket und schlugt

Und gleich den Hunden und Katzen betrlgt?

Annchen von Tharau, das wolin wir nicht tun;

Du bist mein THubchen, mein Schllfchen, mein Huhn.

Was 1ch begehre, 1st lieb dir und gut,

Ich laB den Rock dir, du laBt mir den Hut:

Dies ist uns Annchen die suBeste Ruh,

EIn Leib und Seele wird aus Ich und Du.

Dies macht das Leben zum himmilschen Relch, Durch Zanken wird es der Holle gleich.9

"Das Iled vom Flscher"

Das letzte Beispiel eines "primitiven" Iledes 1st eine Naturballede von Johann Wolfgang von Goethe.

Das Wasser rauscht', das Wasser schwoll,

Ein FIscher saB daran:

Sah nach dem Angel ruhevoll,

Kuhl bis ans Herz hinan:

Und wie er sitzt, und wie er lauscht,

Telit sich die Fiut enpor:

Aus dem bewegten Wasser rauscht

Ein feuchtes Welb hervor. 
Ste sang zu thm und sprach zu ihms

Was lockst du meine Brut

Mit Menschenwitz und Menschenlist

Hinauf in Todes Giut?

Ach, wlibtest du, wle's Mlschlein ist

So wohlig auf dem Grund.

Du klmst herunter, wle du blst.

Und wllordest erst gesund.

Labt slch dle llebe Sonne nicht,

Der Mond sich nicht in Meer?

Kehrt wellenatmend thr Gesicht

Nicht doppelt schbner her?

Lockt dich der tiefe Himmel nicht,

Das feucht verkilute Blau?

Lockt nicht dein eigen Angesicht

Dich her in ewgen Tau?

Das Wasser rauscht' das Wasser schwoll.

Netzt Ihm den nackten FuB,

Sein Herz wuchs thm so sehnensvoll

Wle bel der Llebsten GruB.

Sle sprach zu Ihm--sle sang zu $1 \mathrm{hm--}$

$\mathrm{Da}$ wars un thn geschehn--

Halb zog sle thn, halb sank ex hin

Und wand nicht mehr gesehn.10

DaB das "Primit1ve" gut 1st, sagt Herder in Jahre 1788 in "Ueber die Wurkung der Dichtkunst auf die Sitten der Volker in alten und neuen zelten", einer theoretischen Schrift, "Alles was die Poesle ausdrickt und darstellt, ist gut." II Alle welteren Untersuchungen werden zur Frklarung des Wortes "primitiv" gemacht, das in der Klangform der Sprache erscheint. 
KAPITEL II

\section{"KLANG" UND "STIMME", \\ VERGLEICH VON ZWEI "PRIMITIVEN" ELEMENTEN}

"'Gott sprach durch seine Welt. Ich kann ihn sehn:

Er sprach durchs Wort. Nun kann Ich ihn verstehn!" II

Wenn man die Verhaltnisse zwischen den Begriffen und zwischen den einzelnen Wortern weiter untersuchen will, fingt man am besten mit dem Verb "sprechen" an. Fur Herder hatte die Natur einen Klang, sie tunt, sle "spricht". In elnem anderen Sinne haben die Menschen auch elne "Stinme", sie "sprechen" auch. Belde sind einer Klangform der Sprache fuhig. Inwlefern Ist aber der "Klang der Natur", das 1st die "sprechende Natur", mit der "Stime eines Menschen", mit einem "sprechenden Menschen" zu vergleichen?

In einer seiner ersten Schriften, "Fragmente tber die neuere deutsche Iiteratur", die 1766-1767 erschien, spricht er von den Iebensaltern einer Sprache. Ex vergleicht die Sprache mit der Entwicklung eines Menschen, und sagt, eine Sprache in ihrer "Kindheit" bringe nur "rauhe und hohe Tone" hervor. ${ }^{2}$ Die Sprache, die er damit melnt, ist hauptsalchlich eine Sprache der Impfindungen und Leldenschaften, dle aus THnen und Geborden besteht (201). Solche THne sind heftig, stark ausgedrlickt, natturlich und nur aus den inneren Gefthlen geboren, in anderen Worten "primitiv". "Primitiv" kann also empfindlich, leidenschaftich und nattirlich bedeuten, die Elgenschaften elner "rauhen" und unentwickelten Sprache. In seiner 1770 erschlenenen "Abhandlung tber den Ursprung der Sprache", "welche den von der koniglichen Akademle der Wissenschaften fur das Jahr 
1770 gesetzten Preis erhalten hat", verneint Herder aber, daB solche Geblinden die ganze Basis der menschlichen Sprache sind und sucht anderswo eine Lلsung zun "Problem" des Ursprungs der Sprache. ${ }^{3}$ In welcher Hinsicht war der Ursprung der Sprache aber ein Problen?

Zu Herders Zelt war dieses Froblem ein oft diskutiertes Thema. Zwel von seinen Zeltgenossen, nümich SuBmilch und Rousseau, hatten schon frther ther den Ursprung der Sprache geschrieben, und Herders "Abhandlung" murde geschrieben, um die Argumente dieser zwei Manner zu widerlegen. Johann Peter SuBmilch hat in selner Schrift, "Versuch elnes Beweises, daB die erste Sprache Ihren Ursprung nicht vom Menschen, sondern allein voin Schøpfer erhalten haben", die 1766 in Berlin erschlen, zu bewelsen versucht, daB die menschlliche Sprache "gbttlich" sel. 4 Rousseau, im Gegenteil, schrieb das "Discours sur l'origine et les fondemens de I'inegalite" parmi les hommes", das 1755 in Amsterdam erschien, und schlug vor, der Ursprung der menschlichen Sprache finde sich in den Tierlauten. 5 Als beide Schriften erschienen waren, hat Herder seine "Abhandlung" geschrleben, worin er gleich im ersten Tell den Leser fragt, "Haben die Menschen, inren Naturfthigkeiten Uberlassen, slch selbst Sprache erfinden kUnnen?" und dann versucht er dieses zu bejahen (401). Er fungt in dieser schrift an und sagt, daB ein "empfindsames Wesen", wie der Mensch, und auch jedes Tier, seine Enpfindungen "HuBern" muB, das he1Bt, wenn solch ein Wesen Uberrascht ist oder sich vor etwas furchtet oder erschrickt, muB es "jeden Laut" HuBern, ohne daran zu denken (404). Solche Laute sind "Ach:" und "0:" Sie sind einfache Ausrufe, die den Gefthlen entsprechen. In "Die unmenschliche Mutter" sagt die Tochter dreimals "O meine Mutter!". Ausrufe, die ihren Gefuhlen entsprechen. Diese Gefuhle sind empfindbar, 
naturlich und leidenschaftilch, das ist "primitiv". Diese THne sind deshalb eine Art Sprache, man kUnnte sle elne Sprache der Empfindung, elne spontane Sprache, elne Tlersprache nennen. Diese Töne sind nicht zum Aufschrelben, sle sind nur zum Aussprechen. Solch elnen Ursprung der Sprache findet Hender "sehr naturlich. Ist nicht bloB nicht tbermenschlichs sondern offenbar tlerischs das Naturgesetz elnes empfindsamen Menschen" (412). Aber Herder meint, diese TUne erklyren nicht ganz den Ursprung der menschlichen Sprache.

Was ist also der Unterschied zwischen solch einer Natursprache und der Sprache des Menschen? Der Unterschled llegt darin, daB der Mensch solche TUne auch "mit Absicht" machen kann, er gebraucht seine Vernunft, seinen Verstand und sein BewuBtsein dazu, von Herder durch den Begriff "Besonnenheit" erk1Hut (413). Dies ist ein wichtiges Wort in Herders Sprachphllosophle, und kommt oftmals in dieser Abhandlung vor. erklart das Wort als "die ganze Elnxichtung aller menschlichen Krafte... es Ist die elnzige positive Kraft des Denkens, die, mit einer gewissen Organisation des KHrpers verbunden, bel den Menschen so Vernunft heibt, wie bel den Tieren Kunstfunigke1t wird..." (412). Wle die Tlere mit Kunsttrleben oder Instinkten geboren sind, hat der Mensch dlese "Besonnenheit" vom Anfang seiner Exlstenz an. Krtger exklurt es als die "Elnhelt von Denken, Fuhlen und Wollen". 6 Wie hat der Mensch selne Besonnenhelt gebraucht, um sprechen zu können? Herder schreibt, "Der Mensch, in den Zustand von Besonnenhelt gesetzt, der ihm eigen ist, und diese Besonnenhelt (Reflextion) zum erstenmal frel wirkend, hat Sprache erfunden" (425). Wie wirkt die Besonnenheit aber frel?

Manche Tiere und die meisten Menschen kbnnen sehen, htren und fuh- 
len; ein Mensch kann sich aber einer Sache bewuBt sein; das heiBt, in der Lage von Besinnung kann er wissen, daB er etwas sieht, hbrt oder fthit. In solch einer Lage kann ex die Eigenschaften einer Sache bemerken. Ir geht dann weiter und bemerkt, daB zu jeder Sache oder jedem Gegenstand verschledene Eigenschaften gehtren, und die Folge 1st das Unterscheiden zwischen Gegenstlunden: "Der erste Aktus dleser Anerkenntnis gibt deutIichen Begriff; es ist das erste Urtell der Seele...Dies erste Merkmal der Besinnung war Wort der Seele! Mit ihm ist die menschliche Sprache erfunden!" (426). Der Mensch unterscheidet, inden er eine E1genschaft bemerkt, die zum Kennzeichen einer Sache wird.

Die erste Stufe einer menschlichen Sprache 1st dieses Reden der Seele mit dem Inneren des Nenschen. Herder nennt es in seiner "Abhandlung" einen "Dialog mit der Seele" (435). EIn Tier, wegen Hangel an Besonnenhelt, kann deswegen nicht mit sich selbst reden; das ist also der erste Unterschied zwischen einer Natursprache und einer Menschlichen. Der zweite Unterschied Ist die Fuhigkeit des Menschen, das Wort anderen miteuteilen: "Der erste menschliche Gedanke bereitet also seinem Wesen nach, mit andern dialogieren zu kbnnen. Das erste Merkmal, was 1ch erfasse, 1st Merkwort fur mich, und Mitteilungswort fur andre:" (435). Die menschlichen Gedanken werden zu Worten; in den klingenden Worten besteht die Wirkung. Die Sprache sel "elne Schatzkammer menschlicher Gedanken, wo jeder auf seine Art etwas beltrug: eine Summe der Wurksamkeit aller menschlichen Seelen" (498). Sle 1st gleichfalls der "Same aller Kenntnisse", welche durch die milndliche Lehre weltergegeben sind (505). Ohne die gesprochene Sprache kommen unsere Gedanken nle zu Worten, die unsere Mitmenschen beeinflussen. 
Um alles kurz zusammenzufassen, Ist eln Mensch, wegen seiner Besonnenheit, von den Tieren zu unterscheiden, wegen seiner Besonnenheit, die ihn zu einem Menschen macht, hat er Sprache erfinden kbnnen und auch mlissen: "Also folgt die Sprache aus dem ersten Aktus der Vernunft ganz naturlich" (429). Diese Fuhigkeiten, mit sich selbst und mit anderen Menschen zu reden, unterscheldet den Menschen von allen anderen Tieren. Seine gesprochene, mitgetelite Sprache ist also die elgentumlichste E1genschaft, die dem Menschen gehbrt, und ist von einer Natur-oder Tiersprache zu unterscheiden. Korff sagt: "Fur Herder sollte die Sprache, als die spezifisch menschliche Leistung, der naturliche Ausdruck seines tiefsten menschilchen Wesens" sein." Da "naturlich" auch "primitiv" heiBt, war Sprache am Anfang ganz "primitiv". Antoni schreibt, "In der Sprache fand Herder die Einheit des Menschengeschlechts." 8 Der Mensch allein 1st der Sprache fuhig. Der Mensch kann mit sich selbst reden und auch seine Gedanken anderen mittellen. Ich bin der Melnung, dieser zwelte Bestandteil der menschlichen Sprache war das Wichtigere fur Herder, denn durch die gesprochene Sprache wirkt eln Mensch auf andere Mitmenschen: "Sle sang zu $1 \mathrm{hm}$ und sprach zu $1 \mathrm{hm} . . . "$ Das gesprochene Wort besitzt etwas Magisches und Krlftiges: "Halb zog sie ihn, halb sank er hin/Und ward nicht mehx gesehn." Dle Klangform der Sprache 1st deshalb auch kraftvoll, eine weitere Blgenschaft des "Primitiven".

Neben der Natursprache gibt es aber auch einen "Klang der Natur", der von der Natursprache zu unterscheiden ist. Die Natur spricht, nicht nur in den Naturlauten der Mmpfindung und Leldenschaft der Tiere und Menschen, sondern auch in ihren Bllumen, Blchen, Pflanzen, Winden, whldern und allen anderen Sachen. Das wäre nach meiner Ansicht der "KIang der Natur", die originalen Tone in der Natur. In seinen "Fragmenten" nennt 
Herder die sogenannte zwelte Stufe der menschlichen Sprachentwicklung die Nachahmung der Natur. In seiner "Abhandlung" lehnt er die erste Stufe der rauhen und hohen Tbne der Leldenschaft und Empfindung als die ganze Erklärung der Entwlcklung der menschlichen Sprache ab, und diese zwe1te Stufe wird zur weiteren Erkldrung seiner Theorle des menschlichen Ursprungs.

Nach den ersten Schrecken und der ersten Bewunderung der Natur gab der Mensch den Gegenstlinden Namen. Diese Namen haben zuerst die TBne der Natur nachgeahmt. So sagt Herder in se1nen "Fragmenten" (202). Din Kind, zum Belspiel, ahnt die Klangform elnes Hundes nach, wenn er "Wau, Wau" sagt, dle Klangform einer Blene mit "Sum" oder die Klangform elner Kuh mit "Muh". Solche Laute in der Sprache sind eine Art Klangmalere1. (Diese verschiedenen Wbrter fur denselben Gegenstand ist nicht die Sache zur Hand; es komnt darauf an, welche Merkmale ein Mensch absondert; es 1st die "frele Wirkung" der Besonnenhe1t. Krllger schrelbt: "Herder 16st eigentlich nicht das Problem des Spxachursprungs, sondern das Problem der Entstehung der Sprachnannigfaltigkeit."9 Herder bewelst nicht, woher dle Besonnenhelt kommt, und schllgt vor, viellelcht ware sie also "elnen gottlichen Urgrund erwachsen"" 10 Barnard sagt auch, der Titel der "Abhandlung" sel eine unrichtige Bezeichnung, und empfiehlt den Titel, "The Nature and Function of Ianguage". ") Wenn man also mit "Natursprache" die Sprache meint, die jedes empfindsame Wesen ausspricht und die den Gefuhlen entspricht, so meint man mit "Sprache der Natur" die Tone in der menschlichen Sprache, die den Lauten in der Natur, in Klang der Natur, selber entsprechen: "Das Wasser rauscht", das Wasser schwoll." Und so hbrte man auf die Natur und ahnte sie nach und die menschliche Sprache 
entwickelte sich zu elner klingenden, klangvollen Nachahmung der Natur. Diese zwelte Stufe war auch "primitiv", das 1st klangroll und klingend. In Zusammenhang mit dieser "Sprache der Natur" steht Herders Interesse fur die wilden und ursprtinglichen Sprachen der Welt. Br glaubte, er kblnne aus den wilden Sprachen Spuren von der ersten urspronglichen Sprache bemerken. Deswegen studlerte er viele von den Sprachen, die er "wild" nannte, zum Belspiel die lettische, Iltaulsche, estnische, lappIIndische und andere, um von ihnen ein Gefuhl fur das "Primitive" in der Klangform der Sprache zu bekommen, welches er wleder zu der deutschen Sprache verwendete, um sle zu beleben. Was sind die "primitiven" Elemente In solchen Sprachen? Erstens leben solche wilden Yenschen, von Zivilisation und Kultur meistens unberthrt, der Natur nther. $\mathrm{Da}$ auch thre Sprachen deshalb der Natur nther sind, glaubt Herder, nicht nur in thnen einen hoberen Grad von Natursprache finden zu kbnnen, sondern auch viele Nachahmungen der THne der Natur. Denn die Basis fur dle wilden Sprachen sind Laute in der Natur. Ftir die wilden Menschen bewegt sich alles in der Natur, das heiBt, die Natur ist lebendig. Man erinnert sich an die zweite Stufe der Sprachentwicklung. Das Wasser, der Strom, die Băume. der Wind bewegen sich und wie sie sich bewegen, machen sie verschiedene TBne dabe1. Der wilde Mensch hbrt auf diese THne und ahmt sie nach. Der Klang der Natur ist den wilden Sprachen thnlich. In diesen Sprachen gibt es elne nahe Verbindung zwischen dem "Klang der Natur" und der "Stimme oder Sprache des Menschen". "Primitiv" heiBt auch natbrlich (der Natur nahe) und lebendig (die bewegende Natur). Der wilde Mensch verbindet deshalb Handlung mit Lauten, die eine lebendige Natur charakterisieren. Seine ganze Sprache wird zu einer Art Tonmalere1 oder Lautmalere1. Des- 
halb besteht seine Sprache fast nur aus Verben, die die Bewegungen, die Handlungen der Natur nachahmen. Diese Verba sind "auf die Laute der tbnenden Natur gebauet" sagt Herder in der "Abhandlung" (441). Herder sagt, "das MIteste WHrterbuch war so eln t8nendes Pantheon" (440). "Pr1mitiv" heiBt auch handelnd, tonend und flirs Ohr gemacht.

Da der wilde Mensch alles in der Natur zuerst hbren muB, sagt Herder, das Ohr se1 "der erste Lehrmelster der Sprache" (436). Nur dadurch erfindet der wilde Mensch Wurter, wenn keine laute da sind, das heiBt, wo der wilde Mensch keine Laute in der Natur findet, die seine Gefthle wldersplegeln. Herder erkllurt, das der Mensch "blaB durch das Gehbr die Sprache der Iehrenden Katur empfungt, und ohne das die Sprache nicht exfinden kann so ist das Gehbr auf gewlsse Weise der mittlere seiner Sinne... und das Verbindungsband der ubrigen Sinne geworden" (447). Er erklart es ausfuhrlicher, wenn er sagt,

Auf der elnen Selte liegt das Gefthl nebenan auf der andern 1st das Gesicht der nachbarliche Sinn; die Empfindungen vereinigen sich und kommen also alle der Gegend nahe, wo Merkmale zu Schyllen werden. So wird, was man sieht, 80 wird, was man fuhlt, auch tonbar (448).

$\mathrm{Ob}$ das mehr physlologisch oder philosophisch se1, 1st eigentilch nicht die Hauptsache. Die Hauptsache hier ist Herders Betonung von den Sinnen, Insbesondere dem Sinne des menschlichen Gehbrs, das die Tone der Natur hbren kann. Franz Schultz behauptet auch, Herder stelle das Sprechen und Horen "In den Mittelpunkt aller Sprachschulung" 12 Wozu nutzt ja ein Wort, das nicht ausgesprochen und von anderen gehbrt ist? Die Sprache existiert, um Gedanken auszudrtcken. "Primitiv" heiBt deshalb auch sinnIich, auf das Hbren gegrlindet.

Da der Klang der Natur und die mtundichen Sprachen der w1lden Men- 
schen zu Henders Zelt einander thneIten, indem die Sprachen eine Nachahmung der "tonenden, handelnden, sich regenden Natur" waren (441), worin der wilde Mensch seine inneren, elementaren Gefuhle sich splegein sah, glaubt Herder die erste Sprache mubte auch so gewesen sein und er verbindet diese tonenden Sprachen der Wilden mit einer Art von Gesang, und 1st der Melnung, die erste Sprache se1 Gesang, die erste Form der Poesiel "Aber weder Nachtigallenlied, noch Leibnizens musikalische Sprache, noch ein bloBes Enpfindungsgeschrel der Tiere: Ausdruck der Sprache aller Geschlpfe, innerhalb der nattirlichen Tonlelter der menschI1chen St1mme" (443). Herder denkt hier wohl an die Tonalsprache, sagt Funke. ${ }^{13}$ In Immensee erklurt Reinhard diese Tonalsprache als "Urtbne... sle schlafen in Waldesgrtinden; Gott we1B, wer sie gefunden hat". 14 Nordsleck erklart es als Folgendes: Durch die Sprache wird eln Mensch zu e1nem Schbpfer gemacht, denn er schafft durch die Bilder und Eindrlcke in seiner Seele Worte. Fulr Nordsieck 1st eln Schbpfer von Worten dasselbe wie ein Dichter. $D_{a}$ ein Wortschaffender Mensch ein Dichter se1, sel Poosle (Gesang) die "Muttersprache des menschlichen Geschlechts". 15 Franz Schultz sagt, Musik sel nichts als die schbne "Kunst des Gehbrs", die sich mit der Sprache entwickelte. ${ }^{16}$ Man kann damit ubereinstimmen, dern alles in den wilden Sprachen, und vermutlich auch in der ersten Sprache, war auf das Gehyr gegrindet. Diese musikalische Sprache ist eigentlich eine Art Poesle, wo alles in der Sprache dem Rhythmus der Natur entsprach. Was ist Poesie sonst als Rhythmus und TUne in der gesprochenen, klingenden Sprache? Herder nennt diese rhythmische und musikalische Sprache, dlese Sprache der Poesle "die Natursprache aller Geschøpfe, vom Verstande in Laute gedichtet, in Bilder und Handlung, Leldenschaft und 
lebender Einwliking" (441). In anderen Worten: Die wilden Sprachen enthalten einen "lebendigen Klang der Natur", der sich in elner musikalischen und poetischen Form ausdrickt.

Die Lleder der wilden Madagasker sind Belspiele dleser Musikalltht. Der franzbsische Ritter Parny schreibt lber sie: "Musik und Tanz lieben sie mit Leidenschaft" und ther ihre Lleder schreibt er, ihre Musik sei "einfach, sanft und immer schwermuthig". ${ }^{17}$ Man bemerkt, ihre Lieder sind ohne Strophen. Tatsllchlich scheinen Ihre Lieder und Gesllnge fast Prosa zu sein. Hierin liegt das Wirkungsvolle in diesen Liedern: Sie sind Gesllnge, aber die Gesulnge folgen den natlirlichen, musikalischen und rhythmischen TOnen der gesprochenen Sprache. Man fuhlt diesen Frythmus, wenn man das Lled laut liest. Nach dem ersten Ausruf sagt die Tochter immer: "1ch habe.. Ich habe..habe dich..habe dich.." Nach dem zwe1ten Ausruf benutzt sle die zwelte Person: "wlrst du..welches du...wirst du.." Nach dem dritten Ausruf wird eine einzige, direkte Befehlsform benutzt. "Verkaufe..nicht!" Die ÄuBerungen des Erzthlers sind wie ein hilfloses Amen zu der ganzen dramatischen Geschichte. "Primitiv" meint jetzt auch die musikalische, rhythmische, gesprochene Sprache. Über die Lieder der Wilden In Allgemeinen sagt Herder: "Alle Geslinge solcher wliden Vblker weben um daselende Gegenstunde, Handlungen, Begebenhelten, un eine lebendige Welt:...Die Seele stellet sie sich vor:" Ilutet es in "Osslan" Aufsatz. ${ }^{18}$ Der Leser bemerkt, wle Herder die w11den Sprachen mit dem Wort "lebendig" verbindet. Das ist fur Herder die Hauptelgenschaft dieser Sprachen. Solche wilden Sprachen sind auch naturlich, musikalisch, handelnd und sinnlich, das heiBt, auf des Hbren gegrindet. Sinnlich heiBt aber auch, daB der wilde Mensch durch Metaphern redet, durch lebende Bilder. Die Gefuhle, Sinne und Leidenschaften des 
Menschen sind durch Bilder dargestellt. Wieder in Bezug auf das Lied "Die unmenschliche Mutter" sleht man, wle der Dichter dem Leser Blider schafft. Wer kann sich diese Szene nicht vorstellen und Mitleid mit der Tochter (und der Mutter) haben: Es scheint, mit dem einzigen Wort "schleppen" hat der Dichter dem Leser ein unverglngliches Bild gegeben. Man sieht die Tochter vor der Mutter knlen und flehen. "Primitiv" heiBt auch bildilch.

Als noch eine Elgenschaft solcher wilden Lleder kommt das Wort empfindbar vor. Solche Ileder erwecken in dem Ieser Gefuhle, die alle Menschen besitzen, ungeachtet des Zeltalters, der Nationalitut elnes Menschen, selner Kultur oder auch eines Mangels daran. Das Lled handelt von den elementaren Gefthlen jedes Menschen. Man hort diese Gefuhle jedes Menschen darin sprechen. "Ihr Schrel ist in unsren Seelen wiedergehallt," geht es in einem anderen wilden Gedicht. ${ }^{19}$ In solch einem Gedicht wie "Dle unmenschliche Mutter", wer kbnnte sich nicht mit den stark empfundenen Bitten der Tochter 1dentifizleren? Man empfindet ihren Schmerz und ihre Furcht. Solche Lieder haben die Kraft in sich, alle zu berthren. Herder meint, daB "dle Sprache und Lieder einer alten, wilden Nation ein Studium in den Irrglngen menschlicher Phantasie und Ieidenschaft" sind (440). Beim Studium einer wilden Sprache lernt man die tiefen, inneren und "dunklen" Gefuhle wiedererkennen, mit denen man in einer modernisierten Gesellschaft Kontakt verlor. Solche Ileder sind empfindbar oder "primitiv".

Der Leser bemerkt auch, wle die Tochter ihre Mutter anredet. Die Wilden Uberlegen sich nicht, sle sprechen 1hre Gedanken einfach aus. Sie denken nicht, "Was wlirde man dazu sagen?" oder "Wurde man thel von mir denken?" Die Wilden sind echt, sind "primitiv", in dem Ausdruck ihrer 
Gefthle. Korff sagt:

Da bel thnen noch keine verstandesmaBige Reflexion die Unmittelbarke1t des Erlebens schwllcht und alle Eindrticke deshalb elne ganz andere Wucht besitzen, so hat auch ihr sprachlicher Ausdruck eine ganz andere Unmittelbarkelt und Wucht.20

Herder sagt auch:

Immer die Sache, die sle sagen wollen, sinnlich, klar, lebendig anschauend:...nicht durch Schattenbegriffe, Halbideen und symbolischen letternverstand....zerstreuet, noch minder durch Kunstelelen, sklavische Erwartungen, furchtsamschleichende PoIitik und verwirrende Prlmeditation verdorben - Uber alle diese Schwllchungen des Gelstes seligunwissend, exfassen sie den ganzen Gedanken mit dem ganzen Yorte, und dies mit jenem. Sie schwelgen entweder oder reden im Moment des Interesses mit einer unvorbedachten Festigkeit, Sicherheit und Schbnheit, die alle wchlstudierten Europtler allezeit haben bewundern milssen.2I

Das Wort, das dieses Zitat zusammenfaBt, lst "direkt" oder "unmittelbar". Die Wilden schminken ihre Sprache nicht mit nutzlosen WHrtem und Ausdrlcken, sondern sie sind unmittelbar und direkt in ihrem Reden. Herder nennt es "treffend in jedem Wort".22 In seinem Aufsatz tber "Ossian" sagt er weiter. "Dlese gelehrten Leute, was whren dle gegen die W11den? - ...unverdorbne Kinder, Frauenzimmer, Leute von gutem Naturverstande, mehr durch Tatigkeit als Spekulation gebildet, die sind...die besten Redner unsrer Zeit."23 Noch ein anderes Z1tat gehbrt hierher, numlichs "Die Gedichte der alten und wilden volker entstehen so sehr aus unmittelbarer Gegenwart, aus unmittelbarer Begeisterung der Sinne und der EInbildung und doch haben soviel Wurfe, soviel Sprlinge."24 Von keiner "gebildeten" Gesellschaft in Ketten gehalten und an Regeln gebunden, durfen die Wilden ohne alle gesellschaftlichen Hemmungen ihre Erlebnisse ausdrlicken. In "Die unmenschliche Mutter" redet die Tochter ihre Mutter nicht nur mit den Rechten des Blutes an, sondern auch mit den Rechten eines Menschen. Ihre ausgesprochenen Gefuhle sind direkt, das heiBt, klar, sicher, fest, 
mit einem Wort, "primitiv". Solche Lieder nennt Herder "wahrhaftige Zeugnisse" der "Primitivitut" des Menschen. 25 Sie sind nattrilch, lebend1g, sinnlich, echt, handelnd, empfindbar, musikalisch, direkt, le1denschaftlich, kraftvoll, fest, klar und bildilch.

Da die wilden Sprachen "prinitiv" sind, und da sie fast wie die Natur selbst klingen, ist es schwer, sie aufauschreiben, "Je lebendiger nun eine Sprache 1st, je weniger man daran gedacht hat, sie in Buchstaben zu fassen," he1Bt es in der "Abhandlung" (408). Als Beispiel einer "primitiven" Sprache zitiert Herder die hobrlische Sprache, die fast nur aus Konsonanten besteht, denn die Vokale oder "lebendige Tune" undern sich und sind nicht lelcht aufzuschreiben. Bel diesen Morgenlindern war "die Rede gleichsam ganz Spiritus, fortgehender Hauch und Gelst des Mundes", eine wahre "lebendige Aspiration". die Uberhaupt nicht furs Schreiben war, well man die Tone der Natur nicht deutlich aussprechen und deshalb nicht aufschreiben kann: "Was 1st unschreibbarer als die unartikulierten Tone der Natur?...Je nther eine Sprache....1hrem Ursprunge, desto unart1kullerter" und deshalb unschreibbarer 1st sie (409-410). Es ging hier un ein lebendiges, das ist "primitives", Zwiegesprilch zwischen Gott und seinem ausgewthlten Volke. Gott und Mensch sprachen mitelnander. Es ging zu dleser Zelt um die Klangform der Sprache.

Da die wilden, alten und ursprlinglichen sprachen "primitiv" sind, haben sie auch einen Reichtum an Synonymen: "Je urspringlicher eine Sprache 1st, je htufiger solche Gefthle sich in thr durchkreuzen, desto weniger kbnnen diese sich genau und logisch untergeordnet sein" (455). Er nennt als Belsplel die arabische Sprache, die flinfig wbrter fur einen Ibwen, 200 fur eine Schlange, und 1000 ftr ein Schwert hat, Gegen- 
stunde also, die ein Tell des alltuglichen Lebens eines Arabers sind. Jede Famille, jeder Stamm gebraucht ein anderes Wort, Dinge zu beschreiben. Whhrend die Araber so viele Worter fur Ibwen, Schwert und Schlange haben, haben andere wilde Menschen viele Synonyme fur anderes. Herder gibt als weiteres Beispiel die ceylanische Sprache, die reich an "Schmelcheleien, Titeln und Wortgeprange" ${ }^{n}$ ist, die slamesische, die acht verschiedene Arten von "1ch" und "w1r" hat; und dle Sprache der "wllden Kariben", die eine Sprache fur Manner und eine andere fur Frauen hats "Die Analoglen aller wilden Sprachen bestutigen melnen Satz: jede 1st auf inre Weise verschwenderisch und durftigs nur jede auf eigne Art" (456-457). Solche wliden Sprachen sind zur gleichen Zeit "axm" und "reich", nur auf verschiedene Weise: "Jede dieser Synonymien hingt so sehr mit Sitte, Charakter und Ursprung des Volks zusammen" (457). Herder erkllart diesen Reichtum an Synonymen als eine Unfahigkeit der Wilden, Abstraktionen auszudrllcken, denn den melsten ihrex Wortern liegen Gefthle zu Grunde: "Je ursprthglicher die Sprache, desto weniger Abstraktionen, desto mehr Gefuhle" (457). Meiner Melnung nach hangt dieser Reichtum mit der Freiheit der Besonnenhelt zusammen und mit denjenigen Iigenschaften eines Gegenstandes, die die elnzelnen Menschen absondern, um elne Sache zu beschre1ben. Die Gefuhle splelen hier eine wichtige Rolle, indem der Mensch entweder positiv oder negativ auf eine Sache reaglert.

Die "Primitivitat" der wilden Sprachen macht sie also unschreibbar, reich an Symonymen und auch verlnderlich: "Je lebendiger elne Sprache, Je nther sie ihrem Ursprunge, und also noch in den Zeiten der Jugend und des Wachstuns ist: desto verlnderlicher" (490). Eine Sprache, die nur zum Aussprechen 1st und durch Gefthle auf eine Sache reaglext, kann sich 
leicht verlindern. Die Gefuhle Indern sich und auch die worter, die diesen Gefuhien entsprechen. N1chts ist auf Papler gemalt oder durch Regeln bestimnt. Die gesprochene Sprache existiert, um Gefuhle frel auszudrlcken. Eine verinderliche Sprache ist deshalb eln Merkmal fur elne lebendige, gesunde Sprache, die nur in den Mundern der Menschen existiert. Alle Eigenschaften der "Primitivitut" und die Resultate solcher beweisen das "Krllftige, Machtige, GroBe in den Sprachen der Wilden" (481). 
KAPITEL III

"NATUR" UND "VOLK",
VERGLEICH VON ZWEI ANDEREN "PRIMITIVEN" ELEMENTEN

Der Klang der Natur ist aber heutzutage nicht mit der Stimme des Menschen zu vergleichen. Wie der Mensch sich entwlckelte, entwickelte sich auch seine Sprache. Fur Hexier gibt es immer eine Parallele zwischen der menschlichen und der sprachlichen Entwlcklung. Er drlickt diese Idee in zwel von seinen Schriften aus, in den "Fragmenten" und in seiner "Auch eine Philosophie der Geschichte zur Bildung der Menschheit". Es Ist schon erwhhnt worden, wle er in seinen "Fragmenten" die verschledenen Iebensalter einer Sprache beschrelbt. Als der Mensch ein "KInd" war, drilkite er sich in "rauhen und hohen TBnen" aus; die Sprache war eine der Empfindung und des Gefuhls. Diese Sprache war die Natursprache, die alle empfindsamen Wesen auszusprechen fuhlg sind. Nach diesen "ersten Schrecken und der ersten Bewunderung" der Natur gab der Mensch den verschiedenen Dingen in der Natur Namen, die wle die Natur selbst klangen; es war eine Nachahmung der TOne der Natur, eine Axt von Gesang. Als das Kind Jungling wuxde, erreichte die Sprache ihr poetisches Lebensalter, es kan die Zelt der Dichter und er erzhhlte die Geschichte seiner Zeitgenossen durch Ifeder, und verewlgte dadurch die Keldentaten der Vorfahren. Alles war "auf Laut gestellt" und "das Jugendzeltalter der Sprache 1st ihm daher das klanglich und poetisch schbpferlsche", sagt Funke ther Herder. I Es war der Hohepunkt des "Primitiven" in der Klangform der Sprache.

Der Jungling wird Mann und dessen Sprache ist nicht mehr Poesie, 
sondern Prosa. Man fing an zu schreiben, was "der echten Poesie den TodesstoB" gab. ${ }^{2}$ Dle Sprache wird vollkommener, aber sle verliert damit Ihre naturliche, "primitive" Schønheit, "Je mehr Regeln eine Sprache erhalt, desto vollkommener wird sie zwar, aber desto mehr verliert die wahre Poesle" Ilest man in den "Fragmenten" (203). Das philosophische Zeitalter der Sprache entspricht dem hohen Alter des Menschen. In diesem Zeitalter der Sprache hat sie von ihrem naturlichen Reiz nicht viel thrig; sle wird zwar vollkommen und richtig, aber sie lst nicht mehr "schbner Klang". Und so endet Herders Sprachkrels (201-203). Korff sagt von Herders Lebensaltem der Spracher "Dle Sprache beglnnt als lebendiger Ausdruck und endet als mechanisches Verstlindigungsmittel. Sie 1st inrem Wesen nach erlebtes Symbol und erstaxt schlleBlich zur toten Grammatik. "3 Was ist dem "Primitiven" in der Klangform der Sprache passiert? Um das herauszufinden, muB man wefter mit der Analogie gehen.

Diejenigen, die der Kindheit der Sprache und des Menschen entsprechen, sind die Morgenlander, die Agypter sind das Knabenalter; die PhBnizler sind der "erwachsnere Knabe", die Griechen bedeuten die Jtinglingszeit, wo "alles Jugendfreude, Grazle, Splel und Llebe" war. 4 Homers Geslinge sind "nicht gedichtet, gelesen zu werden; sie wurden gesungen und sollten gehbrt werden...Die griechische Lebhaftigkeit" war auch "Im Vortrage, im Erzthlen und im Extemporieren endichteter Geschichte" anwesend. Bei den Griechen war das Hauptmerkmal auch lebendig oder "primitiv", "Und zwar geschahen die groBten Wurkungen der Dichtkunst, da sie noch lebendige Sage war, da noch keine Buchstaben, vlel weniger geschriebene Regeln da waren." 6 Der Dichter horte alles lebendig in der Natur klingen und ahmte sle nach, Homer sang, "was ex gehbret, stellte dar, was 
er gesehen und lebendig erfaBt hatte". 7 Die Romer reprusentieren das Mannesalter, cder die "Reife des Schicksals der alten Welt". 8 und jetzt lot die Sprache in Ihren hohen Alter, wo alles zu Philosophie gemacht wird. Dieser Kreislauf der Sprache und des Menschen war fllr Herder eine sehr natbrliche Entwicklung von beidem. Herder sagt in den zweiten Naturgesetz in der "Abhandlung" "Der Mensch ist in seiner Bestimmung ein Geschbpf der Hexde, der Gesellschaft, die Fortbildung einer Sprache wird 1hm also nattrilch" (481). Aber diese Aussage muB in solcher Weise interpretiert werden: MuB das "Primitive" in der Klangform der Sprache whrend der Entwlcklung untergehen? Wle kann eine Sprache dieses Element durch alle Lebensalter behalten? Um eine Lbsung zu finden, muB man diese Entw1cklung der Sprache zusammen mit der menschlichen Intwicklung weiter untersuchen.

Whitend die Sprache sich nattrlich entwickelt, verbindet sie die Vergangenhe1t mit der Gegenwart, die Gegenwart mit der Zukunft: "Der Agypter ohne morgenlandischen Kindesunterricht ware nicht Ägypter, der Grieche ohne Igyptischen Schulfle1B nicht Grleche,"9 Die Sprache existiert, um Ideen der verschiedenen Zeitalter mitzutellens "Da hatten EItern den Krels ihrer Ideen nicht fur stch gesammelt, er war zugleich da, un mitgeteilt zu werden," behauptet Herder in der "Abhandlung" (484). Durch die mundliche sprache lehrt der Weltvater den Weltsohn, und der Weltsohn lehrt seinen Weltsohn, und so weiter geht der Fortgang bis ans Ende der Welt. Durch die Sprache lernt ein Kind, wie seine Weltvorfahren dachten und fthlten, was ftur Fehler sle machten und was fil Gutes und Nutzliches sie geschaffen haben. Er baut dann weiter auf diesen Bom den, und dle Kette der Entwicklung wird weiter versturkt. Niemand exis- 
tiert nur fur sich allein; er 1st Immer von seinen Weltvorfahren beeinfluBt und hat auch einen EinfluB auf seine Weltnachkommen "Niemand ist In seinem Alter alleln; er bauet auf das Vorige, dies wird nichts als Grundlage der Zukunft." 10 Diese Weltentwicklung der Menschheit durch die Sprache 1st nattirlich. Herder sagt in selnem vierten Naturgesetz in der "Abhandlung", diese internationale therlleferung der Kulturen und Sprachen sel die hbchste Form der menschilchen Entwicklung, "So haben sich Klnste, Wissenschaften, Kultur und Sprache in einer groBen Progression Nationen hin verfelnert - das feinste Band der Fortbildung, was die Natur gewthlet:" (502). Man erkillut es mit einem Worts Zivilisation: Dlese Entwicklung ist aber auch in einem engeren Sinne zu fassen. In der "Abhandlung" gibt Herder sein drittes Naturgesetz an: "So wie das ganze menschliche Geschlecht unmbglich eine Herde bleiben konntes so konnte es auch nicht eine Sprache behalten. Es wird also eine B11dung verschledner Nationalsprachen" (489). Diese Nationalsprachen existieren, da Familien und Stymme miteinander nicht gut auskommen konnten. Man wird sich an den Babelturm erinnern. Da Menschen verschieden sind und oft andere Ideen als thre Mitmenschen haben, 1st es ihnen eigentum11ch, daB sle schlleBlich gestritten haben, von elnem Ort zu elnem anderen weggezogen oder von anderen Stymmen abgezogen sind. Dadurch entwickelten sie allmuhlich Ihre eigene Sprache, KIIma, Geographie und die neuen Nachbarn haben aber auch einen Einflub auf sle und ihre Sprache gehabt, aber "der Grund von dieser Verschledenheit so naher klelner V8lker In Sprache, Denk-und Lebensart ist gegenseitiger Familien-und NationalhaB" (493). Es ist genau diese Stammsprache, die von allen Mitgliedern eines Stammes oder eines Volks gesprochen wird, daB am besten ein Volk 
genau kennzelchnet. Dle Sprache, die "spezifisch menschliche" Leistung, Ist auch der Schlllssel zum Verstehen des Begriffs "Volk". Was 1st also die Verbindung von "Natur" mit "Volk"?

Antoni betont die "Pflicht gegen die Nation als Pflicht gegentber einer 'natirlichen" Tatsache". Il Wie 1ch es interpretiere, 1st es natorlich, daB das ganze menschliche Geschlecht nicht eine Sprache spricht. Eine Sprache 1st nicht universal und auch nicht individuell. Bs gibt Gruppen, V8lker, bel denen die Sprache sich entw1ckelt. Diese Gruppen existieren nur so lange, wle sle thre mlindliche Sprache bewahren. Nach Barnard ist diese mlindliche Sprache genetisch und organisch bewahrt; genetisch Insofern wie die Eltern ihren Kindern die Sprache lehren, und organisch indem die Kinder das Alte und das Neue in der gesprochenen Sprache verschmelzen. ${ }^{12}$ Gerade hlerin zeigt sich das Veränderliche, das "Primitive" in der gesprochenen Sprache. Hierin zelgt sich auch der Mensch als ein schaffender Gelst, eln Dichter; er schafft sich eine lebendige, "primitive" Synthese vom Alten und Neuen, worin das Ursprling11che Immer daran Tell hat. Durch diese Verschmelzung behlit die Sprache Ihre Lebendigkeit und "Primitivitht". Man arbeltet immer an ihr; sie wird nie fertig geformt, bis der letzte Mensch auf der Erde stirbt. Die mulndiche Sprache kann mit Recht sagen: "Was wirst du ohne mich werden?" Ein Volk kann mit Stolz erklären, "Sie ist mein Leben, mein Gut und mein Geld," worin seine "Seele, sein Fleisch und sein Blut" vermischt sind. Es ist diese lebendige, gesprochene Sprache, die das Wichtigste 1st. Deshalb kritisiert Kerder die Deutschen, die Sprache als Grammatik ansehen und nicht als ein "Werkzeug" zur Bildung, zur lebendigen Synthese. 13 
Auf diese Welse wird der Weltvater zum Stammater, der seinen Stammsohn durch mllndilche Lehre die Sprache seiner Stammvater lehrt. Durch die mundliche Sprache erfthrt er alles von der Geschichte und den Begebenhelten seiner Vorfahren. Dleser Stammsohn lehrt selnen Stammsohn und die Kette dieser Volkskultur geht entweder bis zum Inde der Stamnsprache oder zum Aussterben des Stammes, Es mag sein, wle es will, was flir elnen Namen man Menschen gibt, die dieselbe Sprache sprechen: Familie, Stamm, Volk, Nation. Wenn man das Wort "Volk" auswhlhlt, kann man sagen, nach Herder sel ein Volk eine naturliche Gruppe von Menschen, die wegen Ihres KIImas, threr Geographie, Ihrer Blldung, threr Vererbung, threr KuItur und Ihrer Abnelgung gegen andere Vulker dleselbe Sprache sprechen. Wle die Sprache eln Volk kennzelchnet, kennzelchnet das Volk die Nation. Das Volk 1st die Nation! "Was wirst du ohne mich werden?" Die verschledenen Mitglieder eines Volks sind durch thre lebendige, mllndliche, "primitive" Sprache, das Elgentlimlichste an Ihnen, Innerlich verbunden. Wie jede Person elgentumlich 1st, hat jedes Volk auch elne Individualltat, eine Eigenart. Antonl nennt es eine "Besonderhelt" und sagt, es sel die Pflicht eines Volks, "sich durchzuarbeiten zur elgenen Besonderheit". ${ }^{14}$ Das heiBt, ein Volk muB herausfinden, woher es kam und wohin es gehen will. Nur durch die Sprache ist das mbglich. Im Volke erkennt Hexder d1e "zum zwe1tenmal geschaffene Natur des Menschen'" und geht also auf die Suche nach der germanischen Natur durch die Untersuchung der gesprochenen Sprache. ${ }^{15}$ hofft dadurch, das deutsche Volk zur Erkenntnis zu bringen, daB sein Zweck In der endlosen Fortsetzung seiner "primitiven" Sprache liegt.

Wer gehbrt eigentlich zum Volk? Herder sagt in seinem "An Predi- 
ger", daB dle verschledenen KIassen nicht "abgetellte Raume, sonderm... verschiedene Namen einer unzerteilten Kraft" seien, ${ }^{16}$ Er formt seine Definition vom Volk vom alten Griechenland, wo der KBnig, gleichwie der gemeine Mensch, Mitglieder derselben Klasse waren. ${ }^{17}$ In seiner "Vorrede" klyrt er die Sache fur diejenigen auf, die das Volk als etwas Negatives beurte1lten. Er schreibt, "Volk helBt nicht der Pbbel auf den Gassen, der singt und dichtet niemals, sondern schreit und verstumnelt."18 Mit den Wort "Volk" meint er also den "KHrper der Nationalitut", das heiBt, diejenigen, die Immer in Kontakt mit ihrem eigenen Land blieben und mit dem, was original und echt in Geist des Stammes oder der Nation war. 19 Is waren gerade die einfachen Leute, die meistens von fremden Beeinflubungen unbefunxt blieben und deswegen original und echt waren. 20 Die verachteten, gemeinen Leute waren die Besitzer einer echten und unverdorbenen Kultur. 21

Das Volk mttBte aber nicht nur den gemeinen Mann auf der StraBe, es k\&nnte auch der vornehmste und hbchste Staatsbeamte sein. Volk he1Bt einfach die "primitiven" Menschen, die noch eine lebendige Sprache fortpflanzen. Man findet ein volk und die "primitiven" Menschen in elner wilden Nation; Innerhalb eines Staates unter den Menschen, die immer in Kontakt mit ihren Wurzeln blieben (das he1Bt, nicht die breite Masse, sondern die schypferische, lebendige Gemeinschaft), ${ }^{22}$ und in der Dichtung von Homer, Shakespeare und Goethe. Alle drel sind eine Art "Dichtung der Jinglingszeit", sie sind Beispiele einer unverdorbenen und echten Kultur; alle drel sind flyhig, elne lebendige, "primitive" Sprache zu schaffen. Wie lst es aber mbglich, mit den elgenen Wurzeln in Kontakt zu bleiben und dadurch eine "primitive" Sprache zu schaffen? 
Nur durch diese Sprache des Volks lernt ein Mensch, was sein Volk von den anderen Volkern unterscheldet. Nur durch die Sprache lernt ex seine Vorfahren kennen, wie sie dachten und fuhlten. Nur durch die mulndliche Sprache kann er in gleicher Weise einen EinfluB auf seine THchter und Suhne ausuben. Solch eine Sprache lernt man schon als Xind von seiner Mutter. Deswegen nennt man sie auch Muttersprache. Nur durch diese Muttersprache kann man eine "primitive" Sprache schaffen. Wieso 1st es nux dadurch mbglich?

Wenn man als Kind von seiner Mutter die Sprache lernt, lernt man nicht nur einzelne Worte als Symbole. Mit diesen Worten lernt man auch Gefthle, die mit den Worten verbunden sind. Es lst deshalb nur natarlich, daB unsrer Muttersprache unsre styrksten Gefthle gehoren,

Lebenslang werden diese ersten Eindrlicke seiner Kindhe1t, diese Bilder aus der Seele und dem Herzen seiner Eltern in Ihm leben und wllkken: mit dem Wort wird das ganze Gefuhl wiederkommen...mit der Idee des Worts alle Nebenideen....werden wiederkommen und malchtiger werden als die relne, klare Hauptidee selbst. Auf diese Weise auBert Herder seine Meinungen in der "Abhandlung" (484485). Es sind dlese Gefthle, die dem Volkscharakter entsprechen. Wenn die Gedanken durch die gesprochene Sprache zum Ausdruck komnen, und wenn die Sprache das Elgenttumilchste eines Volks 1st, dann entspricht diese Klangform der Sprache der elgenttmlichen Denkungsweise und dem Gedankencharakter, dem Volkscharakter, elnes Volks. In "Ueber die Fahigkeit zu sprechen und zu horen" behauptet Herder: "Ist dle Sprache eines Menschen, einer menschlichen Gesellschaft schleppend, hart, verworren, kraftlos, unbestimmt, ungebildet, so ists auch gewiB der Gelst dieser Menschen: denn sie denken ja nur in und mit der Sprache." 23 Deswegen findet er Deutsch "stark und zurllckprallend, nicht aber rauh und unaus- 
sprechbar. Sle erscheint ihm wle das Volk, das sle spricht und nur Welchlingen furchtbar und schreckl1ch." 24 Diese Sprache jedes elnzelnen Volks 1st der Ausdruck selner National-oder Volksseele. Herder schrelbt In seine exste Schrift ther die Sprache, "Ueber den FleiB in mehreren gelehrten Sprachen",

Hat also fede Sprache inren bestimmten Nationalcharakter, so scheint uns die Natur blos zu unsrer Muttersprache eine Verbindlichkelt aufzulegen, da diese vielleicht unsrem Charakter angemessener 1st, und unsre Denkungsart ausfullet, 25

Weiter in derselben Schrift schreibt er: "Unsre Muttersprache hat wirkIIch die zusammenstimmendste Harmonie mit unsern feinsten Organen und zartesten Wendungen." 26 Wegen der Synthese vom Alten und Neuen ist die Muttersprache elnes Menschen keine zum Schreiben geschaffene Sprache; sie lebt, nur indem sle gesprochen und geredet wird: "Und wozu kann unsre Muttersprache unentbehrlicher seyn, als zur Dichtkunst und Beredsamkeit." 27 Deswegen ist eine Muttersprache, die naturliche Sprache eines Volks, wie man sle als Kind von selner Mutter lernt, mit elner wilden Sprache zu vergleichen, denn die wilden Sprachen sind auch voll von elementen Gefthlen; gleichwie dle Wilden die Natur nachahmen, so ahmt ein Kind seine Mutter nach, Belde mlndlichen Sprachen sind nattirlich, lebendig, empfindbari mit einem Wort "primitiv". 
KAPITEL IV

\section{HINDERNISSE IN DER ENTWICKCUNG \\ EINER "PRIMITIVEN" SPRACHE UND DICHTUNG IN DEUTSCHLAND}

Das Studium der nattirlichen Entwicklung einer Sprache eines Volks war in den Jahren 1764 bis 1779 elne Hauptbeschuftigung Herders. Die Frage, warum er sich dafur besonders interessierte, kann nur mit der Lage der gesprochenen und geschriebenen Sprache in Deutschland beantwortet werden. Was also veranlaBte Herder in seinen Frthschriften soviel von dem, was ich die "Primitivitat" in der Klangform der Sprache nenne, zu reden? Ein 21 tat aus seinen "Briefen das Studium der Theologie betreffend", obwohl sputer geschrleben, faBt das deutlich zusammen: "Wir verstummeln die Sprache, schreiben kraftlos oder gezlert, kurz, das relne, echte Deutsch, das unsre Vorfahren schrleben, ehe so viele fremde Sprachen in Deutschland bekannt waren, hat sich in der neuesten Zeit ziemlich verloren." "ü Über diese Lage beklagt sich Herder. Das echte, natliriche, "primitive" Deutsch ist verlorengegangen. Es scheint, die Deutschen zu seiner Zeit haben sich 1hrer Sprache geschumt und deswegen fuhrte das Resultat dieses Zustandes zu einer Nachahmung, Übersetzung und Verehrung von anderen. In "Von Ähnlichkeit der mittlem englischen und deutschen Dichtkunst" spricht Herder ther den Fluch der Nachahmung und übersetzung anderers "Parcival, Melusine, Magellone, Artus, die Ritter von der Tafelrunde, die Rolandsmahrchen sind fremdes Gut; sollten die Deutschen denn von jeher bestimmt gewesen seyn, nur zu Ubersetzen, nur nachzuahmen?" 2

$\mathrm{Da}$ Herder eine Nationalsprache, wegen $\mathrm{HaB}$ und Streit gegen ande- 
re, als eine menschliche Elgentumlichkeit ansieht, die ein Volk am besten von anderen unterscheldet, ist es fur ihn deshalb unnatlirlich, wenn man seln Volk und kulturelles frbe verwirft, und fremde sitten und fremde Sprachen annimmt. In "Auch eine Philosophle" lst es ein sarkastischer Herder, der sich dieses Mal gegen die Schriften Humes und Voltaires ausdrilckt:

We elend, als es noch Nationen und Nationalcharakter gab, was fur wechselseltigen $\mathrm{HaB}$, Abnelgung gegen die Fremden, Festsetzung auf seinen Mittelpunkt, vHterliche Voruxteile, Hangen an der Erdscholle, an der wir geboren sind und auf der wir verwesen sollen: einheimische Denkart: enger Kreis von Ideen - ewIge Barbare1: Bel uns sind gottlob: alle Natlonalcharaktere ausge16scht:....wir haben zwar kein Vaterland, keine Unsern, fur die wir lebens aber sind Menschenfreunde und Weltblirger. Schon jetzt alle Regenten Europas, bald werden wir alle die franzbsische Sprache reden: Und denn - Glitickseligkelt: es fingt wieder die guldne Zelt an, 'da hatte alle Welt elnerlel zunge und Sprache! wird eine Herde und ein Hirte werden:" Nationalcharaktere, wo seld $1 \mathrm{hr}$ ? 3

Sie sind in einem Meer von fremden Sprachen, Übersetzung und Nachahmung verschwunden. "Was habe 1ch getan, um diese Sklaverel zu verdienen?"

In Bezug auf fremde Sprachen schreibt Herder in seinem Aufsatz Uber Ossian: "In fremde Sprachen qualte man sich von Jugend auf, Quantithten von Silben kennenzulernen, die uns nicht mehr Ohr und Natur zu fuhlen gibt. ${ }^{4}$ Das heiBt, die Sprachen, die die Deutschen lemen, sind nicht mehr auf das Gehbr gegrllndet; sle entsprechen dem deutschen Charakter nicht mehr; sle sind nicht mehr natlirich, sinnlich und "primitiv".

Warum scheint Franzbsisch die Ileblingssprache der Deutschen geworden zu sein? Tatsllchlich 1st in den Jahren von 1760 bls 1770 die ExbBte ZahI von franz Warum schamten sich die Deutschen ihrer eigenen Sprache? Die Antwort 
liegt teliwelse in der Melnung der Franzosen ther die deutsche Sprache, die etwas Barbarisches habe wegen der vielen Konsonanten. Herder aber verte1digt das, wenn ex behauptet, Deutsch habe auch starkere Vokale und mehr Hauche als Franzbsisch; diese Aspiration "mildert also recht sehr ihre Barbarei der Konsonanten", druckt er in den "Fragmenten" aus (218-220). Nach Funke sollten diese Konsonanten die "Schlagt deutschen Sprache sein. ${ }^{6}$ Aber es sind nicht nur Fremde, die die deutsche Sprache so negativ beurtelien; auch die Deutschen verachteten ihre elgene Volkssprache: "Die Muttersprache ward als elne Mundart der Mutter, der Welber und der Ungelehrten angesehen," liest man weiter in den "Pragmenten" (269). In Breitingers "Critische Dichtkunst" behauptet der Autor: "Solange elne Sprache die Mundart des sinnlichen Volks war, so blleb sie elngeschlossen und unvollkommen, das Denken, Phllosophieren, die schbnen Kunste und Wissenschaften brachten sle zur Vollkommenhelt " (204). Herder meint, die sinnilche Sprache sel voll schonheit; eine vollkommenere Sprache sel richtig und prizis, aber nicht mehr sinnlich und schon. Aber die deutschen Denker und Ifteraten zur Zelt Herders strebten nach dieser Richtigkelt und Korrekthelt der Sprache, obwohl sle die Sprache dann stelf und pedantisch machten, und nach Herder kein echtes, naturilches und "primitives" Deutsch mehr. Gerade in fremden Sprachen fanden die Dichter und Autoren die "richtigen" und "korrekten" RegeIn. Ier englische Kritiker Blair sagt. "'Die Sprache schreltet von der Durftigkeit zum Reichtum, aber zu gleicher Zeit von Feuer und Begeisterung zu Richtigkelt und Bestimmthelt. Der Ausdruck wird sittsamer, aber auch lebloser. " 7 Nach Blair sel die Dichtkunst die Tochter der Elnbildungskraft, der Phantasie, der Originalitut, das heiBt der 
"Primitivityt", und jetzt schreit sie den Deutschen zus "Verkauft eure elnzige Tochter nicht:" 8

Dieser Raub der deutschen Sprache war aber nichts Neues. Er fing schon zur Zeit der pupstlichen Krbnung Karl des GroBen an, als erster Kaiser des römischen Reiches. Damals kam zu Ende die schune Zeit der germanischen Stumme, die von Tacitus als elne "eigne, unverfylschte originale Nation'" beschrleben worden waren (263). Zur Zelt Tacitus war die "Sprache der Romer eine barbarische...Sprache...durch sie suchten die Rumer die Haine der deutschen Tapferke1t, Freihelt und Aufrichtigkelt zu zersturen" (261). Diese Altgexmanen haben tapfer dagegen geklmpft, aber thre "Urenkel nahmen endlich dlese Fessel der Freihelt halb gezwungen, halb willig an" (261). Karl der GroBe sel nicht so groB, wie man frther von inm glaubte; er war "eln Geschlpf von Rom, eln Sohn des Papstes", whhrend selner Reglerungsze1t kam das echte, "primitive" Deutsch zu Ende:

Munche und frinkische Priesterhorden fuhrten, das Schwert in der elnen und das Kreuz in der andern Hand, den Gotzendienst des Papstes, die schlechtesten Trummern der r Hnischen Wissenschaften und den niedrigsten Gassen-und Klosterdialekt der romischen Sprache in Deutschland ein...die lateinische Literatur erstickte den Geist...die Monchsprache fuhrte ewige Barbarel in der Sprache des Landes ein (262).

Solches war Herders Urtell Uber Karl den GroBen. Das war dle groBe Schande, die den Deutschen schon im neunten Jahrhundert passierte und wofur die Deutschen noch im achtzehnten Jahrhundert bezahltens "Kein grbBerer Schade kann einer Nation zugefuget werden, als wenn man thr den Nat1onalcharakter, die Elgenhelt ihres Gelstes und ihrer Sprache raubt" (263). Die Deutschen sind jetzt das genaue Gegentell von ihren echten Vorfahren; sie haben "durch eine langwierlge Knechtschaft Im Denken ganz 
Ihre Natur verloren, sind....unter allen Nationen Furopas am ungleichsten sich selbst" (263). Dieser Selbstverrat und Treubruch an ihren Vorfahren waren vielleicht nicht nur ganz die Schuld der Deutschen. Herder gibt zu, daB Deutschland durch Fremde Immer am meisten gelitten hat, well "selne Lage...es fesselte...0 ware es in diesen Zeitpunkten eine britannische Insel gewesen:" (264). Trotzdem scheint es, die Schuld liege teilweise mit den Deutschen.

Martin Luther war der Mann, der versuchte, die deutsche Sprache den Deutschen wieder treu zu geben. Damals war Deutsch wieder erhuht worden. Man erinnert sich an Luthers berthmtes Zitat,

Man muB nicht die Buchstaben in der lateinischen sprache fragen, wie man soll deutsch reden; sondern man muB die Mutter in Hause, die KInder auf der Gasse, den gemeInen Mann auf dem Markt fragen und denselbigen auf den Mund sehen, wie sie reden, und darnach dolmetschen.9

Um sprechen zu lernen, muB man zuerst horen kunnen und dann die Sprache aufschreiben, wie man sle hørt. Dann wird die Sprache "lebendig" und "primitiv". Funke besthtigt Luthers Behauptungen, wenn er schreibt, "Nur durch Hbren lernen wir sprechen, und wie wir in der Jugend horten, sprechen wir zeltlebens." 10 zur Zeit Luthers hatte die Volkssprache nochmals einen wahren Boden, auf dem sie natlurlich wachsen und sich entwickeln konnte: sie erfreute sich groBer Bellebtheit. Man verband wieder den gemeinen Mann, der ein Tell des wahren Volks blieb, mit einem echten Deutsch. Nach Herder ist Luther derjenige, "der die deutsche Sprache, einen schlafenden Riesen, aufgewecket und losgebunden" hatte (267). Damals waren die Leute keine Sklaven des fremden Einflusses. Selt dem sechzehnten Jahrhundert hat aber die deutsche Sprache "viel von threr Vortreffilchkeit" verloren. Frgang schreibt, 
Since the second half of the sixteenth century German 11terature had gradually become barren of national (folk) feeling. and, in regard to content, had lost touch with the life of the people. Hence the literature of this perlod, with few exceptions, was a spiritless and meaningless mass of words complied according to formal rules or copled from forelon models. 11

In anderen Worten, die Iiteratur war gelstlos und leblos, well sie einfach nichts mit den Massen und mit dem gemeinen Mann zu tun hatte: Sie war nicht auf das "Primitive" in der lobendigen gesprochenen Sprache gegrlindet. Nach Ergang bestand sie aus lauter Worten, die keinen Sinn mehr hatten. ${ }^{12}$ Kein Buch des achtzehnten Jahrhunderts gleicht Luthers B1belubersetzung; Opitz" Deutsch sel ein ganz anderes Deutsch als Iuthers: und "man sahe sle (dle deutsche Sprache) als keine gelehrte Sprache an, denn dazu war allein die lateinische gekront: man achtete sle bloB als die Sprache des Gemelnen Volks" und der Ungelehrten (268-269). Opitz versuchte, elne 11terarische Sprache zu schaffen, aber nicht nach den naturlichen Sprachregeln, sondern nach elner geregelten Grammat1k. Er Interessierte sich ftir das Geschmackvolle in der Sprache. In seinem Buch von der deutschen Poeterey. 1624, das best1mmte Regeln flir das Schreiben der Poesie festsetzte, schrieb er:

Die zlehrligkeit erfodert das die worte reine und deutlich sein. Damit wir aber reine reden mogen/sollen wir uns beflelssen deme welches wir hochdeutsch nennen besten vermbgens nach zue konnen/und nicht derer brter sprache/wo falsch geredet wird/In unsere schrifften vermischen. 13

Leibniz in Unvorgrelfl1che Gedanken, betreffend die Austubung und Verbesserung der deutschen Sprache, 1697, 1nteresslerte sich nicht nur fir Hochdeutsch, sondern auch fur die Etymologle von Worten aller deutschen Dialekte, elnschlieBend das Alt-Got1sche, Alt-Salchsische und Alt-Frankische. $^{14}$ Aber er schrieb viel auf Lateinisch und FranzBsisch. Klopstock wollte auch eine literarische Sprache schaffen, aber selne poetische 
Sprache war Uberhaupt nicht die Sprache der Massen, und sein MaBstab war auch die grlechische Poesie. Lessing hatte auch die Alten gern. Nach Klopstock, Winckelmann und Lessing sollte Deutschland ein neues Griechenland werden, 15 herder erinnert sie aber an die Unmbglichkelt, "Du kannst, Sokrates unsrer Zelt: nicht mehr wie Sokrates wlirken: denn dir fehlt...die Einfalt der Zelten, Sitten und des Nationalcharakters:"16 Man versuchte nachher, die Sprache zu bessern, aber "durch Nachforschen in altdeutschen Wbrtern, wie es der naturlichste Weg gewesen wㅐre, um ihr Charakter auf ihrem Boden zu geben? Nein:"; man ahmte wieder fremde Muster nach, entweder nach der franzlsischen oder lateinischen Art (270-271). Warum "lacken dich nicht dein eigener Himmel und dein elgenes Angesicht?" Man nahm viele franzlsische WUrter in die deutsche Sprache auf; die deutschen Schriftsteller schrieben kein Deutsch, sondern Romisch-oder Akademisch-Iatein; auch Gottsched hat dle deutsche Sprache "viel zu lateinisch (Grammatisch) behandelt", und man verachtete "die alte deutsche Kernsprache" (269-270). Gottsched, wie Opitz, wollte eine reine literarische Sprache schaffen, aber die Basis flir diese nationale Literatur sollte eine Nachahmung aus dem Lateinischen und Franzbsischen sein, denn die Deutschen selen einer originalen literatur nicht flhig. Deswegen tbersetzte Gottsched viele franzlsische Dramen ins Deutsche. Er verstand nicht, daB "original" heiBt, dem eigenen Boden treu bleiben, "primitiv" sein. Nach Funke war Gottsched der "Brzrationalist", dem die "Dichtung...nicht in ihrer kraftrollen Lautform sondern nur in ihrem toten Buchstabenkleld zuglnglich" war. ${ }^{17}$ Nach Herder habe Gottsched "nlcht nur dle altdeutschen Schriftsteller in Ihrer inneren Stllrke nicht verstanden", sondern auch "unsere Sprache tberhaupt entnervt" (269). Er- 
gang sagt, "In general the reform movements which' both Opitz and Gottsched sponsored were purely intellectual. Their efforts were directed toward making the language conform to a certain set of rules." 18 Opitz' und Gottscheds Blicher waren fux andere Dichter und Schriftsteller der MaBstab geworden.

Das Resultat der Nachahmung fremder Muster und Regeln war zwar elne "verschbnerte und gebildete" Sprache, "aber nicht zu dem erhabnen gotischen Geblude, das sie zu Luthers Zeiten... warı sondern zu einen neumodischen Gebdude, das, mit fremden zieraten Uberladen, bel seiner GrbBe klein und unansehnlich ins Auge fullt" (271). Korff nennt solche Nachahmung einen "Ilterarischen Maskenball", eine Fassade, "Dichtung ohne Leben". 19 Herder war einer der ersten, der Deutsch nicht nur als eine geregelte, Ilterarische Sprache ansah, sondern auch als eine gebildete, gesprochene und klangvolle Sprache, eine "primitive" Sprache. Tatsalchlich solite die Erneuerung der Ilteratur durch die lebendige, gesprochene Sprache kommen und nicht ungekehrt.

Aber Herders Stimme klang elne Zeltlang vergebens, Die Nachahmung verwellte. Sie hbrte nicht mit der franzosischen und lateinischen Sprache auf. Es gab auch eine betrllchtliche Nachahmung und thbersetzung der Grlechen und Englander. Herder sagt, die Griechen "sind der Nachahmung wert" (247), aber er verzwelfelte sehr "an (der) bbersetzung der altesten griechischen Dichter" (216). Auch Antonl sagt von Herder, daB "er den Ausweg der thersetzung verwirft, well Poesle und Beredsamkeit in der Übersetzung 'ihren Kern der Stlyke, das Kolorit, den Glanz der Einfalt, den klingenden Rhythmus verlieren" ", besonders bel den Griechen. 20 Diejenlgen Deutschen, dle versucht haben, Homer und andere zu Ubersetzen, 
haben auch den groBen Fehler gemacht, In glelchen St1l zu schre1ben, das heiBt, sle haben einen Hexameter gebraucht. Herder aber sagt, "Wir sind also an die Mensur elnes Hexameters nicht gewthnt" (213). Der Hexameter war die naturliche Sangart der Griechen, aber fur die deutschen Übersetzer yar das nicht naturlichs "Die Prosa ist uns die einzig natirliche Sprache" (206).

Und als ob dieses unnattrliche SilbenmaB nicht Fehler genug ware, haben die Übersetzer nur den Sinn und nicht den Ton, "den klingenden Rhythmus", tbersetzt. Er grelft diejenigen thersetzer an, die das Leben des Autors oder D1chters Ubersetzen und "langwe1lige Erklyrungen" in den Noten weltergeben, ohne den Text kritisch zu beurtellen und ohne "Anmerkungen und Erlduterungen in hohem kritischen Geist" zu geben, Herder meint dabel, nichts sel fur die Literatur geschaffen (249-250). Dasselbe gilt auch fur die Übersetzungen aus dem Englischen. Man hat die engIischen Schriftsteller in "elende oder mittelmaBige Hexameter" zu tbersetzen versucht, Pope in "wlsserichter Frose" und Shakespeare "Im unGleichsten, fast nie getroffenen Ton" (225). Ein guter Ubersetzer sollte wie ein Fremdenfuhrer sein, der den Leser auf eine Reise nimmt und inm den originalen Autor oder Dichter zeigt, "wie er ist" (249). Zu den KrItikern, die behaupten, Klopstock sel ein deutscher Homer, sagt Herder, das sei tlberhaupt nicht wahrs Homer war "arm an Worten und reich an Handlung", whhrend Klopstock einen groBen "Reichtum von Worten" und "Malerel auf der Oberflache" benutzte (253). Die bltesten griechischen Dichter sind also nach Herder nicht Ubersetzbar. Und wenn man griechische oder irgendeine andere Prosa tbersetzen will, muB man Sinn und Ton tubersetzen. 
Man sleht, wie fremde Sprachen. Nachahmung und Übersetzung der Grlechen, Franzosen und Rbmer und deren Regeln die deutsche Sprache, insbesondere die Itteratur, "verdorben" hat und wie sle dadurch thre "Primitivitut" verlor. 


\section{KAPITEL $Y$}

\section{VERBESSERUNG DER DICHTUNG \\ DURCH DAS "PRIMITIVE" IN DER SPRACHE}

Was 1st die LUsung des Problems des verlorenen Volkscharakters durch fremde Sprachen, Übersetzung und Nachahmung anderer? Die Antwort liegt elnfach in dem Begriff "dem eigenen Boden treu" blelben, oder in Kontakt mit den elgenen Wurzeln bleiben. In den "Fragmenten" sehnt sich Herder nach dlesem Boden, nach dem Ursprung, nach den "Primitiven" selnes Landes: "Whre Deutschland bloB... an den Faden selner elgnen Kultur fortgeleitet, unstre1tig ware unsere Denkart arm, eingeschrankt, aber unserm Boden treu, ein Urbild ihrer selbst" (264).

In Bezug auf frende Sprachen, sagt Herder, 1st es elne naturliche Tatsache, daB es verschiedene Nationalsprachen (Volkssprachen) $\mathbf{g}^{1 b t}$, well aber eine Gruppe oder ein Volk nur solange existiert wie es seine eigene Sprache bewahrt und erhalt, ist es durchaus notwendig, die deutsche Sprache zu bewahren und wieder zu erhbhent "Nicht um meine Sprache zu verlemen, lerne ich andre Sprachen...denn sonst verliere 1ch mehr, als ich gewinne. Sondern ich gehe bloB durch fremde Glirten, um fur me1ne Sprache...Blumen zu holen" (283). Das he1Bt, wenn man ins Ausland relst, muB man wie die Bienen sein, "die in zerstreueten Heeren die Iuft durchsuuseln, und fallen auf Klee und bluhende Stauden, und denn helmkehren zur Zelle, mit stlsser Beute beladen, und liefern uns Honig der Weishe1t."I

Die Muttersprache muB also "der Leitfaden" sein, der 1ch also meine Erstinge des Fleisses opfern muB...so hat 
auch die Sprache unserer Vater Reize, die in unserm Auge alle andere tbertreffen....Wenn wir unsre Muttersprache auf der Zunge behalten: so werden wir desto tiefer in den Unterschied jeder Sprache eindringen, Hier werden wir Lllcken, dort UeberfluB hier Reichthum, dort eine Wiste erblickens und die Armuth der einen mit den Schbzzen der andern bereichern kbnnen. ${ }^{2}$

Um die Muttersprache zu berelchern, lernt man frende Sprachen. Man muB der Muttersprache treu bleibens "Wurdest du gleich elnmal von mir getrennt/Lebtest, da wo man die Sonne kaum kennt/Ich will dir.folgen durch WHבder, durch Meer/Durch Eis, durch Elsen, durch feindliches Heer." In Bezug auf die Griechen 1st es wichtiger zu lemen, nicht "was die Alten gedacht", sondern "wie sie zu denken", nicht die Sprache lernen, "In der sie gesprochen", sondern "wie sle sprechen zu lernen" (266-267).

Da fur Herder Ausdruck und Gedanke wle KBrper und Seele untrennbar sind, muB ein Dichter in seiner Muttersprache schreiben, worin man schon als Kind Bilder und Begriffe sammelts "So muB ich ohne Zweifel in der Sprache dichten, wo ich das meiste Ansehen und Gewalt ther die Worte, die grbBte Kenntnis derselben...habe" (282). Ein Autor oder Dichter hat keine Wahl, wenn er am kryftigsten und wikungsvollsten schreiben will. "Wie viel verliert ein Schriftsteller hlebel, dessen Geist nicht durch seine (eigene) Sprache malchtig geformt ist" (283). Tatsllchlich zweifelt Hender daran, da man sich immer an leichtesten in der Muttersprache ausdrllcken kann, ob man whhrend seines Lebens fyhig 1st, zwei Sprachen "vollkommen" zu lernen und zu fassen, deswegen muB der Dichter "seinem Boden getreu bleiben, der tber den Ausdruck herrschen will" (286). Nur in der Muttersprache wird Gedanke und Ausdruck eine Einhelt. Nur durch diese Einheit kann das "Primitive" ausgedrlckt werden. "Dies ist der Muttersprache die stBeste Ruh/Ein Leib und Seele wird aus Ich und Du."

In Bezug auf die Nachahmung und thersetzung der alten griechischen 
Dichter, sagt Herder, solite man nichts von ihnen nachahmen; man sollte sie nur lesen, um ihren Geist zu erfassen, "Der Fluch, der auf dem Lesen der Alten ruhet, wenn wir bloB Worte lernen oder den Inhalt historisch durchwandern oder lsthetische Regeln suchen" (278). Antoni sagt, man muB "die Seele aus den Worten, aus den Taten und aus den Werken erspthen" und nennt solches ein "Sichhinelnfuhlen" in die Werke der Alten, ein Versuch zu Iernen, wie sle dachten. ${ }^{3}$ Man liest die Alten und versetzt sich dann "in das Werk der Dichtung hinein" und hort "jeden graBen Geist, in seiner elgenen Sprache". 4 Herder behauptet, wenn man eine Übersetzung von Homer lese, lese man "nicht mehr Homer, sondern etwas, was ohngeflhr wlederholet, was Homer in seiner poetischen Sprache unnachahmlich sagte" (215). Statt die Grlechen nachzuahmen, soll man sich selbst nachahmen, Herder nennt es elne "Nachahmung unsrer selbst" (251). Man wind sich an ein Gedicht von Herder erinnern, "Der Affe und der Fuchs," die auf eine Fabel von Lessing beruhts

"Ich ahme nach:"

So sprach

vom dunkeln Busch der Affe Nachhall nach.

"Und wer ahmt dir denn nach?" so sprach

der Spbtter Fuchs (er meint, es sel

Herx Aff im Busch) und schlich herbel.

$\mathrm{Da}$ war kein Affe, der da sprach,

"Ich uffe nach!"

Es war der Gottesmensch, der sprach,

"Ich ahme nach:"

Demltig groB, an eigenen Krlften schwach und ahmend nach

durch fremden Trieb, voll Allgewalt

In Gottes und in jeden Tlers Gestalt,

in jedes Art und seinem eignen Willen

jedwedem dienend und Im stillen

Allherrscher, seinem Vater gleich, sleh Menschenart, sleh Menschenrelch!

Als Gott in weiter Welt

der Volker Grenzen stellt, 


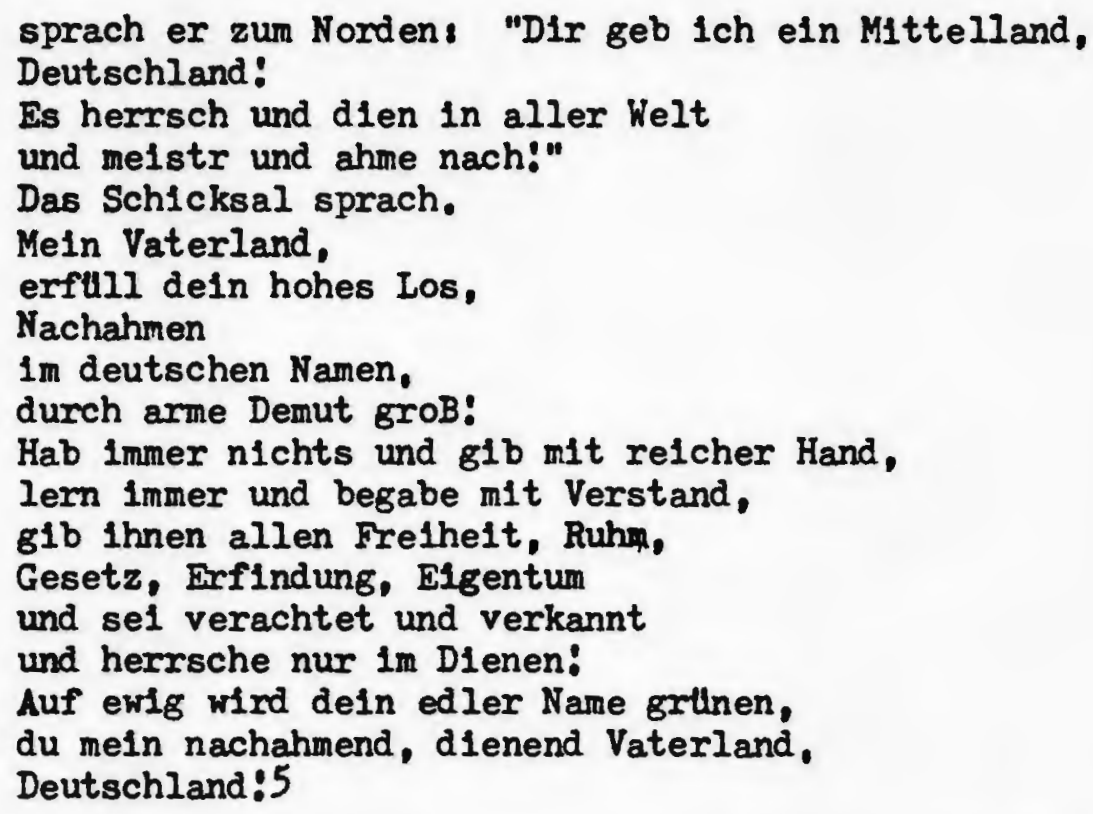

Dlese "Nachahmung unsrer selbst" besteht hauptsllchl1ch aus einem "unsrem Boden treu blelben", das helBt, man soll die Griechen nicht nachahmen, sondern versuchen, wle sie, orlginal, das ist "primitiv" zu sein. Herder behauptet, die Griechen haben auch andere nachgeahmt, aber sie gaben allen eine "ganz neue Natur...nichts Orlentalisches, Phonizisches und Ägyptisches behielt seine Art mehr, es ward griechisch".6 Das sollten auch die Deutschen machen, ngmisch allem eine neue Form, eine Originalitht und ein elgenes Geprage geben. Diese Originalitat kann nur erreicht werden, wenn ein Autor oder Dichter durch die Verbindung von Ausdruck und Gedanken in der Muttersprache seinen elgenen Geist in das Werk hinelnschrelbt. Man kommt also auf den Begriff "dem elgenen Boden treu bleiben" zurldck. Nur durch die deutsche Sprache ebnen die Dichter "elnen Boden, damit er ein Gebaude trage" (199). Herders "Ruf der Stunde", melnt Franz Schultz, Ist, "Deutsche, lernt Deutsch kBnnen! Iernt sagen, was ihr denkt und wollt:"? Er sagt nicht; "Iernt schreiben", sondern "Lernt sagen".

Aber 1st schon so lange her, daB Dichter thre elgenen Gedanken mit 
Ihrem elgenen Ausdruck verbunden haben. Deshalb sprlcht Herder mehrere Male von den groBen Mustern, die notig sind, dle "Mitternacht zum M1ttage" 2u machen (266). Deutschland braucht Originalschreiber:

Durch feine Spekulationen ist nie der Gelst einer Nation geandert, aber durch groBe Beispiele allemal; und neben dieser Hohe1t, ein Muster werden zu können, braucht man bloB ein gutes Auge, andre zu sehen, und einen guten Willen, sich mitte1len zu wollen (245).

Sle brauchen elnige Originalschriftsteller, die Gedanken und Ausdruck in der Muttersprache verbinden, un dem Leser "eln Bild seiner Seele" zu geben, und die nicht an Regeln denken, wenn sle schreiben, sondern versuchen, thre ganze Seele auszudrllcken und zu schreiben, wie man spricht (283). Herder ruft "einige Oxiginalschriftsteller" an und beklagt die damalige Lage in Deutschland als elne "allgemelne Verwirmung", da es "keine hauptstadt und kein allgemeines Interesse" glbt, "kelnen groBen allgemeinen Befbrderer und alIgemeines gesetzgeberisches Genie" (194). Was hindert solch ein Genie hervorzutreten und sich als fuhrendes Muster der Originalityt anzugeben?

Herder gibt eine mbgliche Antwort darauf in den "Fragmenten"s "Je feiner die Regeln sind, die du aus der Natur des Genles herleitest, desto furchtsamer wird der Versuch, der sich endlich nichts Hohers vorsetzt, als fehlerlos zu sein" (245). Die Regeln selber sind nicht schlecht; sie missen nur "primitiv" sein, das heiBt, sie milssen echt und naturlich sein und dem deutschen Charakter und Boden anpassend, "Wiefern hatten auch die Sprachregeln mit den Gesetzen Ihrer Denkart elne Parallele?" fragt sich Herder in den "Fragmenten" (200). Inwlefern sind sie naturlich? Lelder sind sie den Deutschen nicht anpassend; sle sind innen fremd. Aber ein Genle wird nicht durch Regeln und durchaus nicht durch auslyn- 
dische Regein erweckt, die nur das Genle dampfen und wirkungslos machen. Dem deutschen Genie gibt herder folgenden Rats

Begnilge dich also nicht mit grammatischer Schbnhe1t, der Worterwahl, der Stellung der Worte und des toten Rhythmus, denn wenn du da trockne Richtigkelt suchest, wo Schbnhelt dich erfullen soll, so liessest du wie ein MeBktlnstler und Handwerker oder Tagelbhner (280).

"Richtigke1t" 1st also das Gegente1l von "Sch甘nhe1t", wenn Richtigkeit "Vollkommenhe1t" bedeutet, bedeutet es aber auch einen toten statt lebendigen Rhythmus und eine dürre langwe1l1gkelt statt elner fruchtbaren Freiheit des Ausdrucks und Gedankens. Man erinnert sich an Herders Krelslauf der Sprache, als man anfing zu schrelben und dann auch nach Regeln suchter "Je mehr Regeln eine Sprache erhllt, desto vollkommener wird sle zwar, aber desto mehr verllert die wahre Poesle", das lst die lebendige und musikalische Dichtung (203). In einer anderen Schrift sagt Herder: "Jetzt schrieb der Dichter, voraus sang er." 8 Das heibt, er benutzt jetzt Kommas, Punkte, Reime, was vorher die lebendige Stimme besser und styrker ausdrllckte. Jetzt sel die Dichtkunst ohne lebendigen KIang; sie sei nur "Letternkram" und tote Buchstaben; weit von der Natur entfernt:" "Je mehr Kunst an die Stelle der Natur tritt und gemachtes Gesetz (Regein) an die Stelle der lautern Empfindung (der Primltivitat) ...wie 1st da... wahre, wlukkende Sprache der Natur mogilich?" 10

Die Periode dieser herrschenden Richtigkeit, wo alles nach Regeln geschrieben werden muBte, war keine andere als die der AufkIllmung. PoI1tisch wurde der Staat statt der Nation (des Volks) zum Allherrscher. Aber der Staat 1st nicht organisch, er ist mechanistisch, elne Maschine, furs Volk, und nicht Ubers Volk gemecht. Der Staat sollte der Nation, dem Volke, dienen und nicht ungekehrt. Der Staat sollte "seine Gesetze 
sich den 'natlurlichen Gesetzen' des Volkes anpassen". 11 Da das Volk dem Staat die HuBerliche Macht.gibt, ist er mechanistisch und er kann aussterben. Nicht so mit den Mitgliedern elnes wahren Volks, die elne ewige Seele besitzen. Das Volk bekommt seine Kraft von innen, ist organisch, eine nattrilche Gruppe, die sich also nattrilich entwickeln muB. Seine Wurzeln sind tief im Boden, in dem "Primitiven" seines Landes gepflanzt. Solange es seine Sprache aufbewahrt, wird es durch die ganze Weltgeschichte von Innen leben und wirken, ein naturliches Gewllchs, statt einer kUnstlichen Maschine. Wenn der Staat also versucht, die Wurzeln der Volkssprache und Volkskultur auszurotten und diese naturliche, "primitive" Entwicklung des Gewhchses zu verletzen, ist das ein Zeichen der Gefahr flur das Volk und dessen Sprache. Da die Munner der Aufklarung den Begriff "Volk" nicht richtig verstanden haben, haben sie versucht, den Volkscharakter und die gemeine Volkssprache zu ignorieren. 12 Herder warnt den Staat davor und mahnt sle an das romische Reich, das auch versuchte, "dle Nationalcharaktere aller zu zerstbren, alle in eine Form zu werfen, die "Rbmervolk" hieB" bis "es selbst sank". 13 "Im Elende wirst du umkommen." Rom sank auch, well die Germanen (Burgunden, Hunnen, Angeln und andere) im Norden ihren Volkscharakter erhalten hatten und deswegen stgrker waren: "Da ward in Norden ein neuer Mensch geboren." Diese Stumme brachten "statt der Ktinste, Natur... statt der feinen, starke und gute, obwohl wilde Sitten". 14 Da die Natur lebendig ist, ist das Hauptmerkmal bei diesen nordischen V8Ikern "lebendif" oder "primitiv". Diese "Primitivitut" drilckte sich in den Liedern der Germanen aus. Rom konnte die Germanen wegen Ihrer Barden nicht erobern und wegen dieser Barden endlich fiel. In "Ueber die Wurkung" sagt Herder: "Solange es 
Barden gab, war der Nationalgeist dieser V8lker unbezwinglich, ihre Sitten und Gebräuche unausibschbar."15

Die Munner der Aufklyrung waren wie die Rbmer. Sie lebten unter dem "falschen" Eindruck. Sie versuchten nicht nur den wahren Volkscharakter, der am besten im gemeinen Volke erhalten worden war, auszurotten, sondern glaubten auch alle frtheren Zeiten seien nur "Barbare1, Dummheit, Mangel der Sitten" und das Volk unter Ihnen nur Barbaren. Solche "aufgekIHrten" Menschen lobten stattdessen "das Licht unsres Jahrhunderts", das nach Herder nur aus "Leichtsinn, Whrme in Ideen und Kulte in Handlungen" bestand. $^{16}$ Hieso darf der Europder glauben, er sel besser als andere Leute? In dem "Ossian" Aufsatz schrelbt Herders "Wehe...dem Ph1losophen Uber Menschhelt und Sitten, dem seine Szene die einzige ist und der die erste immer, auch als die schlechteste, verkennet:"17 Da die Munner der Aufklymung glaubten, ihre Sprache sel "schbn", richtig und vollkommen und präzis, meinten sie auch, sie seien besser als andere "wilde" Menschen und der gemeine Mann. Fir sie hatten die Wurter "wild", "Volk" und "primitiv" eine negative Bedeutung. Sie verstanden nicht, daB "primitiv" echt und naturlich heiBt; daB "Volk" nicht nur den gemeinen Mann bedeutet, sondern alle, die "primitiv" waren und ihre Originalitut auf ihrem elgenen Boden suchten: und daB "wilde" Menschen, glelch wle das wahre Volk, auch "primitiv" waren, da sie ihrem Ursprung und der Natur nahe bleiben. In "Ueber die Wurkung" sagt er: "Nationen, die wir Wilde nennen," sind "oft gesitteter als wir sind." 18

Fur Herder enthielten solche "wilden" Menschen elne beneldenswerte "Primitivitat". Sie sind ein gutes Beisplel flur den Ausdruck echter, natorlicher Gefthle. Herder redet die Munner der Aufklumung an, wenn er 
In der "Abhandlung" sagt: "Die Kunst, die einen griechischen Palast bauete, zeigt sich bel dem Wilden schon im Bau einer Waldhltte...konnte jene arme Hutte nicht der Ursprung der Baukunst sein?" (503). So ist es auch mit der Sprache. Hat Herder ihnen nicht schon gezeigt, daB andere Kulturen immer auf die vorhergegangenen bauen? Was waren die Deutschen ohne die Ägypter, Griechen und RÖmer? Viele Philosophen zur Zeit Herders glaubten, der "primitive" Mensch sel etwas Unverschumtes, Unerhbrtes, als ob "Dummheit" sehr "unbegreiflich" sel; Herder erkllart weiter in der "Abhandlung" aber, "wild" ("primitiv") sel sehr "natlirlich", Indem es der erste Zustand des Menschen ist, dle "gebildeten Deutschen" haben nur von anderen gelernt (502). In einer anderen Schrift luBert ers "Auch die Griechen waren einst...Wilde, und selbst in den Bllthen ihrer schthsten Zeit ist welt mehr Natur, als das blinzende Auge der Schollasten und Klassiker findet." 19

Aber die frtheren unmittelbaren Leidenschaften der Wilden "'lauschen gewissermaBen hinter eingefuhrten Anstandigkeiten" " die Menschen von heute "unterdrlcken oder bemlnteln Ihre Leidenschaften'", sagt der englische Kritiker Blair. 20 Nichts von der ursprilnglichen "Primitivitat" der Deutschen bleibt tbrig oder wenn es auftaucht, wird wleder schnell unterdrllckt. Antoni sagt: "Der Kampf gegen die Vernunft war zu einem Kampf fur die...langsame, Individuelle und nattrliche Entfaltung der Nationen (V8Iker) geworden."2l

Literarisch angesehen bedeutet die Aufklarung "Erstarmung, Mechanislerung, Tod. Sie bedeutet Ordnung an Stelle von Schbpfung," an der Stelle von "Primitivitat". 22 Diese 1iterarische Periode erwartete von einem Dichter, daB er alles rationalisiere; Vernunft, und nicht die le- 
bendige gesprochene Sprache, sollte die Motivierung zum Schreiben sein. Das Resultat war elne mechanische Dichtkunst. In "Von Ähnlichkelt" sagt Herder: "Unsre klassische Literatur ist Paradlesvogel, so bunt, so art1g. ganz Flug, ganz Hohe und - ohne FuB auf die deutsche Erde", sie sel. namlich eine Nachahmung anderer und deren Regeln. 23 "Was lockst du me1ne Brut/M1t Menschenwitz und Menschenlist/Hinauf in TodesGlut?" Herder 1st ja Uber die Lage der deutschen Literatur und des Denkens seines Jahrhunderts sehr besorgt und bekllmmert. In der "Abhandlung" klagt er:

Es 1st fllr mich unbegrelfilch, wie unser Jahrhundert so tief in die Schatten, in die dunkeln Werkstutten des KunstmuBigen sich verlieren kann, ohne auch nicht einmal das werte, helle Licht der uneingekerkerten Natur erkennen zu wollen. Aus den grbBesten Heldentaten des menschlichen Geistes... sind Schulubungen im Staube unsrer Lehrkerker, aus den Melsterstllcken menschlicher Dichtkunst und Beredsamke1t Kinderelen geworden, an welchen grelse Kinder und junge KInder Phrasen lernen und Regeln klauben. Wir haschen ihre Formalityten und haben ihren Gelst verloren; wir lernen ihre Sprache und fthlen nicht die lebendige Welt ihrer Gedanken.....Da sollen dle stumpfen, spyten Gesetze der Grammatiker das Gbttlichste sein, was wir verehren, und vergessen die wahre gottliche Sprachnatur...Die Sprachbildung ist in die Schatten der Schule gewichen, aus denen sie nichts mehr fur die lebendige Welt wirket (481).

Die Schriften der Deutschen "laBen sich weder lesen, noch høren. Sie en muden". ${ }^{24}$ Horen, Sprechen, Schreiben - so geht es der Reihe nach. Wenn man nicht "primitiv" schreibt, das heiBt, wenn man nicht fur ein lebendiges Publikum schreibt, das seinen Schriften zuhbrt, schreibt man umsonst.

Herder war ein fuhrendes Belspiel dieser Art vom Schreiben, die auf dem HBren, auf der Klangform der Sprache beruht. Funke sagt Uber Herders Schriften, daB sie "blutvolle Lebendigkelt" enthalten. Eln Grund dafur 1st, daB Herders Frau, Caroline, die Vorleserin seiner Werke wurde. Wenn diese Werke sich nicht gut anhbren lieBen, wtlde er sie umschreiben. Er 
schrieb, als ob er sprifche, oder laut duchte. Deswegen war auch Herders schriftliche Sprache klangvoll, lebend1g, "primitiv", well er "Immer den lauten Vortras 1m Sinne" hatte, als er schrieb, 25 frr schrieb, wie er sprach und benutzte Ausrufe, Doppelpunkte, Verktrzungen, Fragen und Wlederholungen, um seine Ideen auszudrllcken. Blackall nennt solches "linguistic gestures". 26 Herder selbst erklyrts "Wohl den Schriftstellem unter uns, die da schreiben, als ob sle hyren, die da dichten, als ob sle süngen" (283). Wie bel den Grlechen ging es bel Herder um die Klangform der Sprache in Dramen, Lyrik, Vortrkgen, und besonders in den Liedern. Alles in der Poesle mtaBte laut vorgelesen oder gesungen werden: "Homers Vers.... ist kein Schulen-und Kunsthexameter, sondern das Metrum der Griechen, das in ihrem reinen und feinen Ohr, in ihrer klingenden Sprache zum Gebrauch bereit lag."27 Homer hat von dem geschrleben, was er wuBte und hurte. Er hat seine Verse geschrieben, wle die Griechen elgentlich sprachen. Darin lag seine GrbBe. Deswegen sagte Herder, er kbnne sogar den Nachhall von Homers Lieder noch hbren. ${ }^{28}$ Nur dadurch kann das "Primitive" in der Sprache, alles was sinnlich, melodisch, stark, klangvoll, rhythmisch und kruftig in der gesprochenen Sprache ist, sich HuBern. Leider war Herder aber eine Ausnahme. Er war den Kritikern in Deutschland sehr kritisch gegentber:

Haben Sle es da nicht oft bemerkt, wie schydlich es uns Deutschen sel, daB wir keine Elisionen haben oder uns machen wollen? ...uns qullen diese schleppenden Artikel...aber wer unter uns wird zu elidieren wagen? Unsre Kunstrichter zthlen ja Silben und können so gut skandieren:29

Jemand der versuchte zu schrelben wle er sprach, also "lebendig", wurde aus den literarischen Xreisen ausgestoBen. Derjenige, der eine Nationalliteratur auf einem lebendigen volkstumlichen Boden bauen wollte, wurde 
sogar "Barbar" genannt, "elne Nachteule unter den schbnen, buntgekleideten, singenden Gefiedern" der "klassischen, sylbenzthlenden Literatur". 30 Nach den Theoretikern der Aufklyrung war Irgendeine Art Volksliteratur der Ausdruck des "ungebildeten Volkes", des gemeinen Mannes. Seine "Lieder waren vom Standpunkt einer aufgeklarten Kunst in der Tat nichts anderes als der unbeholfene und ungeschulte Ausdruck simpler Menschen und primitiver Zustande."3l Aber wenn diese Kunst nur wllBte: "Ach, wtlBtest du, wie's Fischlein ist/So wohlig auf dem Grund (den wahren Boden)/Du kämst herunter, wie du bist/Und wirdest erst gesund."

Die Literatur und insbesondere die Lieder des Volks kommen ja "aus den Erlebnissen des Lebens" und der "unmittelbaren Natur". Sie kommen aus dem Inneren des Menschen und sind deshalb Zeugnisse der Ursprlinglichkeit oder des "Primitiven" des Menschen. 32 Herder definiert ein Lied wie folgt: "Vom Lyrischen, vom Lebendigen und glelchsam TanzmaBigen des Gesanges, von lebendiger Gegenwart der Bilder...davon... .hungt das Wesen, der Zweck, die ganze wundertatige Kraft ab, die diese Lieder haben. '*33

Im Liede scheint also das Universalmittel gegen die fremden Sprachen, die thersetzung und Nachahmung anderer und die Regeln der Aufklarung zu sein. Die Erscheinung wahrer Genies, die wie helle Sterne andern den Weg bereiten werden und eine Originalitat in die Iiteratur des Landes bringen werden, ist auch als Heilmittel nicht zu vergessen. Aber "ein Originalschriftsteller im hohen Sinne der Alten ist... bestundig ein Nationalautor", ein Volksautor, und Deutschland hat ihren Volkscharakter schon lungst verloren oder unterdruckt; nlemand schrelbt noch fllr die Deutschen ein reines, klares, "primitives" Deutsch, behauptet Herder in den "Fragmenten" (283). Die Endlbsung des Problems liegt also in der 
Wiederentdeckung seines elgenen Volksgeistes und Volkscharakters durch Lieder, welche dann vielleicht einlge Originalschriftsteller und Dichter hervorbringen werden.

Diese lebendige Welt des eigenen Charakters ist aber nicht im Auslande zu finden, sondern auf elgenem Boden und in dem "Primitiven" ihres eigenen Volkscharakters. Wo liegen ihre Wurzeln? Teilweise liegen sie in der Vergangenheit. Um in die Zukunft zu gehen, muB sich ein Volk seiner Vergangenheit bewuBt sein; es muB wissen, woher es kommt; es muB mit seinen Wurzeln Fllhlung aufnehmen. Aber die Kette, die die Vergangenheit mit der Gegenwart und mit der Zukunft verbindet, war zerbrochen worden, als die Deutschen ihren Ursprung verleugneten. Um wieder eins zu werden, milssen alle Deutschen wieder ihre Vergangenheit entdecken und dann ein festes Geblude auf eigenem Boden zu bauen anfangen.

Die anderen Wurzeln liegen in dem wahren Volk, in den Menschen, die Ihr kulturelles Erbe nie vergaBen! "Da wir ...kelnen abstrakten Stubenphilosophen zum Erfinder der Sprache brauchen; da der rohe Naturmensch, der noch seine Seele, so ganz wie seinen Korper, aus einem Stllck fthlet, uns mehr als alle sprachschaffende Akademien... ist," behauptet er in der "Abhandlung" (477). Mit diesem "Naturmenschen" ist hier nicht nur der "Wilde" gemelnt, sondern auch solche Menschen, die, obwohl von der Geschichte vergessen, immer in Kontakt mit ihren Wurzeln blieben.

Tatsuchlich glaubte Herder zwel Quellen entdeckt zu haben, worln er die Seele des germanischen Volkes erkannte. Eine war der schottische - 6 Dichter Ossian, ein Beispiel des "Naturmenschen", und die andere das deutsche Mittelalter (die Vergangenheit). Wie von den Alten, sollte man aus der Vergangenhe1t, der Quelle der Nation, neue Inspiration und neues 
Leben bekommen. Dort, glaubte Herder, war die Basis fur einen neuen Anfang, fur die Erneuerung der Kultur und die Erweckung einer echt deutschen Literatur. 34 Es war am Ende des Mittelalters, daB Deutschland anfing, den Geist seines Volkscharakters zu verlieren. Deswegen muB man zurllck zum Mittelalter gehen, um diese verlorene Volksseele durch die Volkspoesle der Zeit wieder zu erringen. ${ }^{35}$ obwohl fur Herder jedes Alter nur "elnmalig" war und er das Mittelalter als kein Ideal ansah, kormte man wohl davon etwas lernen. 36 Dort im Mittelalter, und nicht in Grlechenland oder Irgendwo anders, war der Gelst des deutschen Volkes verborgen. Und in der elgenen Volkspoesie, die noch unter den Bauern und in der Dichtung von Ossian lebte, konnten die Deutschen die Begebenheiten 1hrer Geschichte lernen, und was fur Helden und Heldentaten es damals gab. 37 In der alten Volkspoesie und Liedern war die gesprochene Sprache am lebendigsten erhalten.

Zurllck also in die Vergangenheit und was wichtiger 1st, zurlek in das "Primitive" des wahren Volks: HOrt den Vorfahren zu: HOrt dem Volk zu: Zurlick zu den elgenen lebendigen Wurzeln; zurllck zum naturlichen Boden; zurllck zum Klang der lebendigen, echten und unverfllschten Sprache des Liedes: Lasset die Deutschen nicht nur im Sammeln und Lesen der Lleder anderer wilden Stumme ein Gefuhl fur das Echte, Originale, NaturI1che und "Primitive" bekommen, sondern lasset die Deutschen auch im Sammeln der elgenen Literatur, Mythologle, Geschichte und insbesondere Lieder Ihren elgenen Charakter wiederfinden.

In der "Abhandlung" hat Herder schon behauptet, die erste Sprache sei eine Art Gesang. In "Auch elne Philosophle" hat er den Krelslauf der Sprache gezelgt, und wie die Grlechen diesen Gesang zur hbchsten 
Sch8nhelt gebracht hatten. Herder behauptet, die Lieder der Alten enthalten Gesunge, Geschichte, Sprache, Denkart, Sitten und Taten eines Volks, sie sind einfeltig, stark, rthrend, voll von Gefuhlen, wahrem Sang und klang, und reich an Handlung. ${ }^{38}$ wie die Natur selber sind sle lebendig; sie t8nen, sie widerspiegeln echte und natlurliche Gefuhle. In "Von Ähnlichke1t" welst Herder auf die Tatsache hin, daB die alten Kombdien aus Spottliedern und die Tragbdien aus Chbren entstanden. ${ }^{39}$ Er fuhrt forts

Alle unpolizirte v8lker singen und handeln... Ihre Gesllnge sind das Archiv des Volks, der Schatz ihrer Wissenschaft und Religion, ihrer Theologie und Kosmogenien der Thaten inrer vater und der Begebenheiten Ihrer Geschichte, Abdruck ihres Herzens, Bild ihres, hauslichen Lebens in Freude und Leid, belm Brautbett und Grabe. 40

Dlese Lieder zeigen innen, wer sle waren, wer sle sind, und was sle werden kÖnnen. Sle vereinigen die Menschen von innen. Wenn die Chroniken die politischen Gedanken und das politische Leben eines Volks beschre1ben, so sind Ihr Glaube, Ihre Mythologie, Ihre tiefen Gefuhle in ihren Liedern beschrleben: "So 1st das menschliche Herz und die volle Einbildungskraft nie wlirksamer als in den Naturgesangen solcher Vulker. Sie bfnen das Herz, wenn man sie hbret, und wle viele Dinge in unsrer ktinstlichen Welt schliessen es zu:" 41

Deswegen 1st fur Herder das Lied das Besondere an einem Volk, etwas, was ein Volk am besten kennzeichnet. Vom Lesen seiner Schriften fullt einem auf, das Lied enthlit die "primitiven" Elemente in der Sprache. Is charakterlsiert die Klangform einer Sprache am besten. Das heiBt, durch die Lleder elnes Volks hbren wir sle sprechen. Das Lled ist eine "Stimme des Volks". Aus seiner "Vorrede" kommt, "Gesang... fordert das Ohr des HUrers...Als Buchstaben-und Sylbenkunst... whre er 
gewiB nle entstanden." 42 Lebendiger Gesang ist nur mbglich durch den Gobrauch von Dialog, Kehrreimen, Ausrufen, Elisionen, Wiederholung, Fragen, Sprlingen und Wurfen; durch den Relchtum an Bildern und Gefuhlen; durch den Mangel an Partikeln und einer geregelten Wortstellung; und durch einen einfachen Inhalt und einfache Melodie, alle Sachen, die der Sprache * des Liedes eine Spontane1tyt, Lebendigkeit und Originalityt geben und sie "primitiv" machen, das ist naiv, einfach, melodisch, ungektinstelt, bildlich, dramatisch, filrs Horen und singen bestimmt, sinnlich, konkret, organisch und durch eine mlndiliche Tradition veränderlich. Herder nennt solche Elgenschaften "Pfelle dieses wilden Apollo, womit er Herzen durchbohrt". 43 Hier gehbrt ein berlhmtes zitat aus dem "Ossian" Aufsatz

Je wilder, d.1...je lebendiger....ein Volk ist...desto wilder, d.1. desto lebendiger... mllssen auch....seine Lieder sein! Je entfernter von klinstlicher, wissenschaftlicher Denkart, Sprache und Letternart das Volk ist? desto weniger mussen auch selne Lieder furs Papier gemacht und tote Lettern Verse sein. 44

Das Lied "Die unmenschliche Mutter" ist deshalb "primitiv", wir hbren die Tochter sprechen und empfinden ihren Schmerz. Ihre echten und spontanen Ausrufe und Fragen bewegen das Herz des Lesers ebenso wie der einfache und dramatische Inhalt.

Durch das Lautlesen und Singen von "Annchen von Tharau" bemerkt man den einfachen Rhythmus und den Gebrauch von Fragen. Die dritte Strophe wurde zu einem Kehrreim gemacht. Man bemerkt auch die Inverslon: "Was lch begehre, 1st lieb dir und gut," und auch die Elisionens "Lieb", statt "Llebe", und in gleicher Weise "KHm"", "schlahn", "stahn", "Sonn", "schlleB"", "wolln" und "laB". Der Inhalt behandelt die universalen Themen der Llebe zwischen Mann und Frau und die mbgliche Trennung zwischen ihnen, Erlebnisse aus dem Leben vieler Menschen. Der Sänger 
spricht seine Gellebte an. Dieser Gebrauch der ersten Person wirkt in seiner Lebend 1gkeit und Einfachhe1t.

Auf glelche Weise enthylt "Das Lied vom Fischer" auch die Merkmale eines einfachen, volkstülichen Liedes. In stilistischer Hinsicht gibt es auch Elisionen: "rauscht"" "wie"s", "ewgen", "wars", "geschehn" und "gesehn", eine Wiederholung von "Das Wasser rauscht", das Wasser schwoll", Fragen, und den Gebrauch von Dialog, "Sle sang zu him und sprach zu ihmo" Inhaltlich 1st es wieder einfach und doch kraftvoll und zauberhaft. Beim Lautlesen hort man fast das Wasser rauschen und am Boot platschern und wird von der Kraft der Natur Uberwaltigt. Der Dichter schafft dem Leser Bilder, wle beim ersten Lied. Man hbrt nicht nur das Wasser rauschen und das Weib singen, sondern sleht auch den Mann im Boot sitzen, das mysteriUse Weib aus dem Wasser emporkommen, das Angesicht des Mannes sich im Wasser widerspiegeln und endlich den Mann in Wasser verschwinden. Der Leser fuhlt irgendwie, durch den einfachen Rhythmus und Inhalt, die machtige Kraft des gesprochenen Wortes und fuhlt sich auch ins Wasser hinuntertauchen. Wenn das Meer das Vaterland und dessen Wurzeln reprlsentiert, so ist das Weib die magische Kraft der eigenen Dichtung. Das Lled erzthlt die Geschichte der magischen Kraft der gesprochenen Sprache und ist auch ein Beispiel von dem, was Herder mit dem Wort "primitiv" meint, lebendig, spontan, original und kraftvoll.

Diese magische Kraft des "Primitiven" lebt am besten in der Dichtung. das ist in einem Lied, sel es ein Lied der Wilden, ein Lied der einfachen Leute oder ein Lied von einem berluhmten Dichter wie Goethe. Alle drei Beispiele sind meiner Meinung nach eine Art Lied aus dem wahren "Volk". Es 1st schon erwahnt worden, mit dem Wort "Volk" meint Her- 
der diejenigen, die immer echt, natirlich und von dem Kthstlichen in der Gesellschaft unberlhrt sind. Die Wilden sind deshalb eine Art Volk, ebenso wle die Bauern und einfachen Leute und auch groBe Dichter wle Homer, Shakespeere, "Ossian" und Goethe. Es 1st dieses "Volk", das fyhig ist, eine dauernde Literatur zu schaffen, well es mehr mit dem Herzen als mit dem Kopf denkt. Das Herz schafft sich dauernde Begriffe und Eindrlicke, well diese Eindrllcke hauptsllchlich von den Gefllhlen ausstrbmen. Diese Bilder und Begriffe sind von innen geschaffen, nicht von auBen durch die Vernunft.

Herder verband also das Wort "Volk" und "lied" und pragte 1771 das Wort "Volkslied". Da Volk und Natur eine Verbindung miteinander haben, ist also ein Volkslied ein Naturlied, der Ausdruck des "Primitiven", der Lebendigke1t. Das Volk lebt durch seine Lleder. Ein Volkslied 1st daher das beste Beisplel des "Primitiven" In der gesprochenen Sprache: Man hort, und nicht liest, die Sprache. Hierin 1st dle lebendige Sprache der Vater, der Volksseele, aufbewahrt. Hierin spricht das Volk durch Bilder. In seiner "Vorrede" zum zwelten Tell der Volkslledersammlung schreibt Herder noch weitere Gedanken Uber das Volkslied. Wieder kommt das Wort "lebendig" vor, insbesondere in Bezug auf die Griechen, die Poesie so definiert haben:

Sie lebte im Ohr des Volks, auf den Iippen und der Harfe lebendiger Sunger; sie sang Geschichte, Begebenhelt, Geheimnis, Wunder und Zeichen: sle war die Blume der Elgenart elnes Volks, seiner Sprache und seines Landes, seiner Geschyfte und Vorurtheile, se1ner Leidenschaften und AnmaBungen, seiner Musik und Seele.45

Ernst Klusen behauptet, es gabe vor Herder keinen "Allgemeinbegriff vom Volkslied".46 Er meint, das Volkslied nach Herder sel ein "Gemeinbesitz der Nation" oder "Besitz der gesamten Population" und vor thm 
wären die Lieder nur "Gruppenbesitz".47 Wiora behauptet, im Gegenteil, das Volkslied muBte nicht nur eine "allgemeine Verbreitung" haben. 48 Man könte mit ihm einstimmen. "Volkslied" he1Bt ein lied vom Volke, von der "schøpferischen Gemeinschaft", entweder von den W1lden, von den gemeinen Leuten oder von einem volkstlumlichen Dichter, der fir das Volk spricht und die Volksseele in seinen Liedern widerspiegeln laBt. In Immensee fragt Elisabeth Reinhards "Wer hat doch aber die schönen Lieder gemacht?'" Reinhard erklurts

Sie werden gar nicht gemacht; sle wachsen, sie fallen aus der Luft, sle fliegen Uber Land wle Marlengarn, hierhin und dorthin, und werden an tausend Stellen zuglelch gesungen. Unser eigenstes Tun und Leiden finden wir in diesen Liedern; es ist, als ob wir alle an ihnen mitgeholfen hatten. 49

In Deutschland gab es solch eine Geneinschaft, die aus Bayern, Schwaben, Thuringen, Sachsen, und vielen anderen Tellen des gemeinen "Volks" bestand. Jeder Tell dichtete Lleder, die vielleicht nur von dem einen Teil verstanden waren. Vielleicht waren sle sphtter zum "Gemeinbesitz" geworden, aber im Anfang muBte das nicht sein.

Durch diese lebendigen Lleder der Wilden, "Ossian", Griechen und anderer begeistert, versuchte Herder, als einer der ersten, nicht nur dem deutschen Iied eine Ehrenstelle in der deutschen Literatur wiederzugeben, sondern sah das Volkslied als den Schllissel zur Erneuerung der deutschen Sprache und Literatur. Er ruft jetzt den Deutschen zu, ihre eigenen Lleder zu sammeln, um wieder Geschichte, Gedanken, Glauben und Taten ihrer Vorfahren zu finden

GroBes Reich, Reich von zehn V8lkern, Deutschland! Du hast keinen Shakespeare, hast du auch keine Gesünge deiner Vorfahren, deren du dich rllhmen kUnntest? Schwelzer, Schwaben, Franken, Bayern, Westphaler, Sachsen, Wenden, Preussen, Ihr habt allesamt nichts? Die Stimme eurer Vater 1st verkiungen und schweigt im Staube? Volk von tapfrer Sitte, von edler Tugend, und Spra- 
che, du hast keine Abdrllcke deiner Seele die Zeiten hinunter?50

Die Deutschen haben aber nicht auf ihre eigene Literatur und Geschichte gebaut und

aus liltern Zeiten haben wir also durchaus keine lebende Dichtere1, auf der unsre neuere Dichtkunst, wle Sprosse auf dem Stamm der Nation gewachsen whre...WIr arme Deutsche sind von jeher bestimmt gewesen, nie unser zu blelben, 1mmer die Gesetzgeber und Diener fremder Nationen, ihre Schicksalsentscheider und ihre verkaufte, blutende, ausgesogne Sklaven. 51

Er klagt welter: "Hohe, edle Sprache: grosses, starkes Volk: Es gab ganz Europa Sitten, Gesetze, Erfindungen, Regenten, und nimmt von ganz Europa Regentschaft an." 52 Was muB geschehen, um die Deutschen aus ihrer Gleichgdlitigkeit zu stoBen? Der Manessische Kodex, ein Manuskript von mittelalterlichen, deutschen Gedichten, wurde entdeckt, aber es gab kein Erstaunen dartber: "Der Schatz selbst liegt da, wenig gekannt, fast ungenutzt, fast ungelesen....Man lasse in Deutschland nur Lieder drucken, wie sle Ramsay, Percy u.a. haben drucken lassen, und hure, was unsre geschmackvollen Kunstrichter sagen:" 53

Ja, die Engländer, von germanischen Stummen, haben es richtig gemacht. Sie haben eine Volksliteratur, well sle mit "Beglerde" Ihre Volkslieder gesammelt haben, "Wle welter whren wir, wenn wir diese Sagen und Volksmelnungen auch so gebraucht hytten....und unsre Poesle so ganz darauf gebaut wilre, als dort Chaucer, Spenser, Shakespeare auf Glauben des Volks baueten. "54 Beide Nationen haben eine thnliche Frluhgeschichte und dieselben Vorfahren, aber warum hat Deutschland keine groBen Dichter wie Shakespeare und Spencer; warum hat Deutschland keine Volksliteratur und Volkslleder gesammelt? Die Antwort liegt wheder in der Klangform der Spraches In den "Fragmenten" sagt Herders "EIn Volk, das ohne poetische Sprache groBe Dichter...gehabt hatte, 1st ein Unding" 
(199). Das Poetische in der Sprache heiBt das Lebendige, das Kraftrolle, das "Primitive" in der Sprache, was eine Zeltlang verloren ging. Aber es 1st nicht zu spat, "Der Schatz liegt noch da," vielleicht tief begraben, aber doch zuglnglich. Er wuBte, daB Deutschland noch Hoffnung hatte, wenn die Leute sich nur bemthen wlirden, Lieder zu sammeln: "In mehr als einer Provinz sind mir Volkslieder, Provinziallieder, Bauernlieder bekannt, die an Lebhaftigkeit und Rhythmus und Naivitut und Styrke der Sprache vielen derselben gewiB nichts nachgeben wllden. "55

Deswegen bittet er und fleht seine Freunde an, jeder in seinem Dorf nachzusuchen und Lleder zu sammeln. Deutschland hat genau so viele schone Lieder, wenn man sich nur die Zelt nehmen wllrde, sle zu sammeln:

Nun wir milssen Hand anlegen, aufnehmen, suchen, ehe wir Alle klassisch gebildet dastehn, franzbsische Ileder singen, wie franzosische Menuets tanzen, oder gar allesamt Hexameter und horazische Oden schreiben.... Legt also Hand an, meine Brlder, und zeigt unsrer Nation, was sle 1st und nicht 1st: wle sie dachte und fuhlte, oder wie sie denkt und funlt: Welche herrliche Stllcke haben da die Englander bel ihrem Suchen gefunden: Freilich nicht furs Papier gemacht und auf $1 \mathrm{hm}$ kaum lesbar; aber dafur voll lebendigen Geistes, im vollen Kreise des Volks entsprungen, unter ihnen lebend und willkend, 56

Der Zweck solch eines Sammelns sollte zwelerlei seins der Hauptzweck liegt in der Entdeckung der elgenen klangvollen, gesprochenen Sprache der Deutschen, wie er es in den "Fragmenten" yuBert: "Wird es bald sein, daB thr eure Sprache durch Untersuchungen, ihre Weltweisen: durch Sammlung und Krit1k, Ihr Philologen: durch Meisterstllcke, ihr Genles: zu derjenigen macht, d1e...'allen aber Natur' verschaffen kann?" (226). Was 1st diese "Natur" anderes als das "Primitive" und Echte, das auf dem elgenen Boden whllchst. Da liegt der Schatz begraben. Der Schatz liegt in den verschiedenen volkern Deutschlands: "Die alte wendische, schw㚲ische, sulchsische, holsteinische Mythologie....wäre wahrlich eine 
Fundgabe fur den Dichter und Redner seines Volks. "57 Herder fordert die Deutschen auf zu beweisen, "daB Deutschland wtirklich seine Lieblingshelden, Originalsujets, National-und Kindermythologien gehabt und mit eignem Gepräge bearbeitet haben". 58

Von James MacPhersons Fragments of Anc1ent Foetry, 1760-1764, begeistert, fing Herder selbst an, Volkslieder zu sammeln. Ein paar Jahre spater, 1778-1779, hat er seine elgene Volksliedersammlung herausgegeben, die "nebst vortreflichen, melstens so gut wle unbekannten und verlornen deutschen Lledern, die schbnsten Gesunge andrer v8lker, zum The1l wahre Meisterstlicke des sturksten Gefthls und der hochsten simplizitt" enthalt. 59 Nach seiner Frau hatte er auch die Originalmelodien herausgegeben, "wenn er diese noch selbst hatte ordnen kbnnen". 60 Herders Sammlung, die nur zwanzig deutsche Lieder enthylt, war international geworden. Diese Lleder schlieBen die Lleder der Wilden, der Ungebildeten der Welt und auch Lieder von Goethe, Shakespeare und Homer ein. Alle drei waren Ihm Beispiele wahrer Genles aus dem Volk, deren Dichtung "nicht aus der Kultur, sondern aus dem Feuerherzen der Natur" entspringt. 61 Ein wahrer Volksdichter ist jemand, der von seiner elgenen Kultur und elgenem Land treulich erzthlt, elne Art Reflexion der Volksseele.

Der Nebenzweck der Sammlung war die Umwertung des Wortes "primitiv" in Bezug auf die Poesie. Antonl sagt, "Die Idee der 'Volkspoesie" ... bezeichnet numlich in der europalschen Kultur das Ende der Auffassung der Kunst als eines Schmuckstllckes und eines anmutigen Splels."62 Der Begriff "primitiv" ist nicht mehr etwas Negatives. Das Wort meint jetzt echt, unverdorben, naturlich, original, spontan, sinnlich, kraftvoll, organisch, lebendig, ungeklnstelt, wirkungsvoll, stark, klar, mu- 
sikalisch, dramatisch und empfindbar, positive Eigenschaften, die nicht nur die Wilden beschrelben, sondern auch alle Mitglieder der wahren v81ker in der Welt, die mit dem Kerzen und nicht mit dem Verstand handeln. Clark sagt: "Herder's Folksongs did more than any other one publicetion of the century to advance in Germany the empathic approach to folk poetry." 63 


\section{KAPITEL VI}

\section{SCHIUBFOLGERUNG}

Das Volkslied war also die Quelle fur die Frneuerung der deutschen Literatur, und das Volkslied hat auch Goethe, Elchendorff, Heine, Uhland, Morike und andere beeinfluBt. Durch sie war die deutsche Iiteratur splter berelchert worden. Herder wies die Deutschen auf ihre elgenen unzahlbaren Schytze und ihren eigenen literarischen und historischen Reichtum zurtick. Man mllBte sich nicht mehr schlmen, Deutsch zu schreiben und zu sprechen. Man sollte nicht nur englische, grlechische und franzbsische Dichter rlhmen und preisen, sondern auch deutsche Dichter. Man mtbte nicht mehr die gemeinen Leute verspotten, sondern sie als den Schlussel ansehen, um in die Vergangenheit zurllckzukehren, un dort den Volksgeist wieder zu erringen.

Das Volkslied war auch der Schlussel zum Verstehen des "Primitiven" als der echte und wahre Ausdruck aller v81ker. Alle Volker haben Lieder, die die Basis elner echten, nattrlichen und volkstumlichen Iiteratur sein kbnnen. Wegen des Volksliedes sind alle v8lker gleich. Deswegen konnte Herder sagen: "Alle Ileder sind meine Zeugen: Aus Lapp-und Estland, lettisch und polnisch und schottisch und deutsch und die ich nur kenne, je alter, je volksmaBiger, je lebendiger, desto kuhner und werfender."I Herder war selbst das Muster, das Deutschland verlangte; er verband in dieser Sammlung durch das Wort "primitiv", das nur in der gesprochenen Volkssprache und im Volkslied lebt, selne Idee der Nationalitht und Humanityt. Diese Lieder waren eigentlich Stimmen der Vergangen- 
65

heit und der Gegenwart, Stimmen von vielen verschiedenen vblkern der Welt; Vblker, die durch inre Lieder die lebendige Sprache fortpflanzen, damit ihre Nachkommen eine Idee bekommen konnen, wer sie sind, woher sie stammen, und wohin sie gehen. Sie sind wahre Zeugnisse ihres Charakters. Das "Primitive" in der Sprache, die nattriliche Stimme eines Volks, ist durch die klangvollen Lieder lebendig erhalten. 
FUBNOTEN

\section{KAPITEL I}

1 Rudolf Haym, Die romantische Schule (Hildesheims Georg OIms Verlagsbuchhand lung, 1961$)$, S. 809.

2 Carlo Antoni, Der Kampf wider die Vernunft, tber. Walter Goetz (Stuttgart: K. F. Koehler Verlag, 1951), S. 240.

3 H. A. Korff, Geist der Goethezeit, 4. Auflage (Le1pzig: Koehler \& Amelang, 1958), I, 117 .

4 Robert R. Ergang. Herder and the Foundations of German National1sm (New York, Octagon Books, Inc., 1966), S. 171.

5 Antoni, S. 240.

6 Johann Gottfried Herder, "Volkslleder," Herders Werke, heraus. Heinrich Kurz (Leipzig, Bibliographisches Institut, 1887), II, 343. FuBnote 1.

7 Herder, "Volkslieder," heraus. Kurz, II, 348.

8 Johann Gottfried Herder, "Volkslieder," Johann Gottfried Herder: Werke in zwel Banden, heraus. Karl-Gustav Gerold (Minchen: Carl Hanser Verlag, 1953), I, 214.

9 Herder, "Volkslieder," heraus. Gerold, I, 108-109.

10 Ibid., I, 239-240.

11 Johann Gottfried Herder, "Ueber die WUrkung der Dichtkunst auf die Sitten der v8lker in alten und neuen Zeiten," Herders summtliche Werke, heraus. Bernhard Suphan, VIII (Berlins Weidmannsche Buchhandlung, 1892), 342.

\section{KAPITEL II}

1 Johann Gottfrled Herder, "Von Ähnlichkeit der mittlern englischen und deutschen Dichtkunst, " in The Romantic Tradition in Germany: An Anthology, heraus. Ronald Taylor (Londons Methuen and Co., 1970), S. 5.

2 Johann Gottfried Herder, "Fragmente Uber die neuere deutsche Literatur," in Sturm und Drang: Kritische Schriften, heraus. Erich Loewenthal (Heidelberg: Verlag Lambert Schneider, 1963), S. 201. (Alle we1- 
teren Nachschlagen in den "Fragmenten" werden in den Text mit Nummern angegeben.)

${ }^{3}$ Johann Gottfried Herder, "Abhandlung tber den Ursprung der Sprache," In Sturm und Drangs Kritische Schriften, heraus. Erich Loewenthal (Heidelberg: Verlag Lambert Schne1der, 1963), S. 399. (Alle weiteren Nachschlagen in der "Abhandlung" wexden in den Text mit Nummern angegeben.)

4 F. M. Barnard, heraus, u. Uber., Johann Gottfrled Herder on Social and Political Culture, von Johann Gottfried Hender (Cambridges Cambridge Univ. Press, 1969), S. 120.

5 Barnard, s. 126.

6 Manfred Krllger, "Der menschlich-gbttliche Ursprung der Sprache: Bemerkungen zu Herders Sprachtheorie," Wirkendes Wort, 17 (1967), 3.

7 Korff, I, 117.

8 Antoni, S. 268.

9 Krlger, s. 7.

10 Ib1d., S. 10 .

11 Barnard, S. 21.

12 Franz Schultz, Klassik und Romant1k der Deutschen, 3. Auflage (Stuttgart: J. B. Metzlersche Verlagsbuchhandlung, 1959), I, 202. 994.

13 Erich Funke, "Herder und der Sprachlaut," PMLA, 67 (Dez, 1952),

14 Theodor Storm, Immensee, heraus, Elmer 0. Wooley (Boston: D. C. Heath \& Co., 1936), s. 66.

15 Reinhold Nordsieck, "Herders On the Natural History of Poetry," Tennessee Studies in Literature, 7 (1962), 13.

16 schultz, I, 210.

17 Herder, "Volkslieder," heraus. Kurz, II, 343.

18 Johann Gottfried Herder, "Auszug aus einem Briefwechsel Uber Ossian und die Lieder alter Volker," Johann Gottfrled Herder: Werke in zwe1 Bunden, heraus. Karl-Gustav Gerold (Mtunchens Carl-Hanser Verlag, 1953), I, 864.

19 Herder, "Volkslieder," heraus. Kurz, II, 348. 

20 Korff, I. 137.
21 Herder, "Ossian," I, 851-852.
22 Ibid. I, 862.
23 Herder, "Ossian," I, 852.
24 Ibid. I. 855.
25 Korff, I, 136.

KAPITEI III

1 Funke, S. 996.

2 Ibld., s. 996.

3 Korff, I, 141.

4 Johann Gottfried Herder, "Auch eine Philosophie der Geschichte zur B1ldung der Menschheit," in Sturm und Drang: Kritische Schriften, heraus. Erlch Loewenthal (Heldelberg: Verlag Lambert Schnelder, 1963). S. 589-599.

5 Funke, S. 997-998.

6 Hexder, "Ueber die wurkung," vIII, 369.

7 Johann Gottfried Herder, "Vorrede zum zweiten Theil der Volksliedersanmlung," Herders Werke, heraus. Heinrich Kurz (Lelpzigs Bibliographisches Institut, 1887). II, 65.

8

Herder, "Auch eine Philosophie," S. 599.

9 Ibid.. S. 590 .

10 Ibid.. S. 609.

11 Antoni. S. 242 .

12 Barnard, S. 32.

13 Johann Gottfrled Herder, "Ueber die Fuhigkelt zu sprechen und zu horen," Herders Sämmtliche Werke, heraus. Bernhard Suphan, XVIII (BerIin: Weldmannsche Buchhandlung, 1883), 384.

14

Antoni, S. 251, 256.

15 schultz, I. 183. 
$\therefore \quad 16$ Johann Gottfrled Herder, "An Prediger," Herders S4mmtliche Werke, heraus. Bernhard Suphan, VII (Berlin, Weldmannsche Buchhandlung, 1884), 299.

17 Johann Gottfrled Herder, "Brlefe zu Befurderung der Humanityt," Herders Slmmtliche Herke, heraus. Bernhard Suphan, XVII (Berlins Weldmannsche Buchhandlung, 1881), 26.

18 Herder, "Vorrede," II, 70.

19 Ergang, S. 195.

20 Tbid.. S. 195.

21 Ibid., S. 206.

22 Ernst Klusen, "Anmerkungen zum Begriff 'Volkslied' und seinem Alter," Die Musikforschung, 24 (1971), 173.

23 Herder, "Ueber die Fuhigke1t," XVIII, 385.

24 Funke, S. 994.

25 Johann Gottfrled Herder, "Ueber den Fle1B in mehreren gelehrten Sprachen," Herders Symmtliche Werke, heraus. Bernhard Suphan, I (Berlin: Weldmannsche Buchhandlung, 1877), 2.

26 Ibid., I, 6.

27 Ibid., I. 6.

\section{KAPITEL IV}

1 Schultz, I, 200.

2 Herder, "Von Ähnlichkeit," S. II.

3 Herder, "Auch eine Philosophle," S. 640.

4 Herder, "Ossian," I, 852.

5 Ergang, S. 153.

6 Funke, S. 994.

7 Korff, I, 140.

8 Ibid, I, 140.

9 Martin Luther, "ther Dolmetschen," in The German Heritage, 
heraus. R. H. Phelps, rev, Ausgabe (New Yorkı Holt, Rinehart \& Winston, 1958), S. 55.

10 Funke, S. 1006.

11 Ergang, s. 177.

12 Ibid., S. 177.

13 Martin Opitz, Buch von der Deutschen Poeterey, heraus. Richard Alewyn (Tubingen: Max N1 emeyer Verlag, 1963), S. 24.

14 W. W. Chambers, "Language and Nationality in German Pre-Romantic and Romantic Thought," Modern Language Review, 41 (Okt. 1946), 383.

15 Ergang, S. 183.

16 Herder, "Auch eine Philosophle," S. 655.

17 Funke, s. 996.

18 Frgang, S. 146.

19 Korff, I, 149.

20 Anton1, S. 242.

KAPITEL V

1 Herder, "Ueber den Fle1B," I, 7.

2 Ibid., I, 5-6.

3 Antoni, S. 253.

4 Ibid., S. 243.

5 Johann Gottfried Herder, "Gedichte," Herders Werke in funf Bunden, heraus. W1 lheln Dobbek, 3. Auflage (Welmar: Aufbau Verlag, 1964), I. 9-10.

6 Herder, "Auch eine Philosophie," S. 598.

7 schultz, I, 204.

8 Herder, "Ueber die Wurkung," VIII, 412.

9 Ibid.., VIII, 413.

10 Ib1d., VIII, 342. 
11 Antoni, S. 249.

12 Tbid., S. 272.

13 Herder, "Auch eine Philosophie," S. 600.

14 Ibid., s. 611.

15 Herder, "Ueber die Wurkung," VIII, 392.

16 Herder, "Auch elne Philosophle," S. 618.

17 Herder, "Ossian," I, 839.

18 Herder, "Ueber die Wurkung," VIII, 392.

19 Herder, "Von Ännlichke1t," s. 19.

20 Korff, I, 139.

21 Antoni, S. 275.

22 Korff, I, 141.

23 Herder, "Von Ähnlichkeit," S. 15.

24 Herder, "Ueber die FHhigke1t," XVIII, 389.

25 Funke, S. 1009-1010.

26 Eric A. Blackall, "The Imprint of Herder's Linguistic Theory on His Early Prose Style," PMLA, 76 (Dez. 1961), 514.

27 Hexder, "Vorrede," II, 65.

28 Ibid., II, 66.

29 Herder, "Ossian," I, 864.

30 Herder, "Von Ähnlichkeit," S. 15.

31 Korff, I, 136.

32 Tb1d., I, 136.

33 Ib1d., I, 137-138.

34 Christa Kamenetsky, "The German Folklore Revival in the 18th Century: Herder's Theory of 'Naturpoesie," Journal of Popular Culture, 6 (Frtuhling 1973), 846.

35 William A. Wilson, "Herder, Folklore and Romantic Nationalism," 
Journal of Popular Culture, 6 (Fruhling 1973), 824.

36 Robert T. Clark, Jr., Herder, H1s Life and Thought (Los Angeles: Univ. Of Callfornia Press, 1955), S. 253.

37 wilson, S. 825.

38 Herder, "Von Ähnlichkeit," S. 17.

39 Tbid., s. 19.

40 Ibid., s. 18.

41 Ibid., s. 19.

42 Herder, "Vorrede," II, 64.

43 Herder, "Ossian," I, 836.

44 Ibid., s. 836.

45 Herder, "Vorrede," II, 64.

46 Klusen, S. 173.

47 Ibid.. S. 173.

48 Walter Wiora, "Das Alter des Begriffes Volkslied," Die Musikforschung, 23 (1970), 422.

49 storm, s. $64,66$.

50 Herder, "Von Ähnlichkeit," s. 16.

51 Ibid., s. 14 .

52 Ibid.. S. 15.

53 Ibid.. S. 13-14.

54 Ibid., s. 12.

55 Herder, "Ossian," I, 859.

56 Herder, "Von Ähnlichkeit," s. 16.

57 Ibid., s. 12.

58 Ibid., 5. 11.

59 Ibid., S. 25. 
60 Funke, S. 1002.

61 Korff, I, 143.

62 Antons, S. 258.

63 clark, S. 259.

KAPITEL VI

1 Herder, "Ossian," I, 856. 


\section{BIBLIOGRAPHIE}

Antoni, Carlo. Der Kampf wider die Vernunft. Übersetzt von Walter Goetz. Stuttgart: K. F. Koehler Verlas, 1951.

Barnard, F. M. Herausgeber und Übersetzer. Johann Gottfried Herder on Social and Political Culture. Von Johann Gottfrled Herder. Cambridge: Cambridge Univ. Press, 1961.

Blackall, Eric A. "The Imprint of Herder's Iinguistic Theory on His Early Prose Style." PMLA, 76 (Dez. 1961), 512-518.

Chambers, W. W. "Language and Nationality in German Pre-Romantic and Romantic Thought." Modern Language Review, 41 (Okt. 1946), 382-392.

Clark, Robert T., Jr. Herders His Life and Thought. Los Angeles s Univ. of California Press, 1955.

Frgang, Robert R. Herder and the Foundations of German Nationalism. New York? Octagon Books, Inc., 1966.

Funke, Erich. "Herder und der Sprachlaut." PMLA, 67 (Dez. 1952), 989-1010.

Haym, Rudolf. Die romantische Schule. Hildesheims Georg Olms Verlagsbuchhand lung, 1961 .

Herder, Johann Gottfried. "Ueber den Fle1B in mehreren gelehrten Sprachen." Herders S4mmtliche Werke. Herausgegeben von Bernhard Suphan. 33 Bande. Berlini Weidmannsche Buchhandlung, 1877. I, 1-7.

- "Briefe zu Beforderung der Humanitut." Herders Sammt1iche Werke. Herausgegeben von Bermhard Suphan. $3 \overline{3}$ BAnde. BerIIn: Weldmannsche Buchhandlung, 1881. XVII, 1-132.

- "Ueber die Fuhigkeit zu sprechen und zu høren." Herders Simmtliche Werke. Herausgegeben von Bermhard Suphan. 33 Bunde. Berlins Weldmannsche Buchhand lung, 1883. XVIII, $384-390$.

"An Prediger." Herders SHmmtliche Werke. Herausgegeben von Bernhard Suphan. 33 Blnde. Berlini Weldmannsche Buchhandlung, 1884. VII, 225-312.

von Heinrich Kurz. " 4 Bolkslieder." Herders Werke. Herausgegeben
1887. II, 79-417.


"Vorrede zum zweiten Theil der Volksliedersammlung." Herders Werke. Herausgegeben von Helnrich Kurz. 4 Blinde, Le1pzig: Bibliographisches Institut, 1887. II, 64-78.

- "Ueber die Wurkung der Dichtkunst auf die Sitten der V81ker in alten und neuen Zeiten." Herders Summtliche Werke. Herausgegeben von Bernhard Suphan. 33 Bunde. Berlin: Weldmannsche Buchhandlung, 1892. VIII, 334-436.

"Auszug aus einem Briefwechsel tber Ossian und die Lleder alter vblker." Johann Gottfrled Herder, Werke in zwe1 Banden. Herausgegeben von Karl-Gustav Gerold. Munchen: Carl Hanser Verlag, 1953. I, 831-874.

- "Volkslleder." Johann Gottfrled Herder: Werke In zwe1 Bynden. Herausgegeben von Karl-Gustav Gerold. Munchen: Carl Hanser Verlag, 1953. I, 69-407.

"Abhandlung ther den Ursprung der Sprache." In Sturm und Drang: Kritische Schriften. Herausgegeben von Brich Loewenthal. Heidelbergs Verlas Lambert Schneider, 1963. S. 399506.

- "Auch eine Philosophie der Geschichte zur Bildung der Menschhe1t." In Sturm und Drang: Kritische Schriften. Herausgegeben von Erich Loewenthal. Heldelberg Verlag Lambert Schnelder, 1963. S. 579-670.

- "Fragmente Uber die neuere deutsche Literatur." In Sturm und Drang: Kritische Schriften. Herausgegeben von Erich Loewenthal. Heidelberg, Verlag Lambert Schne1der, 1963. S. $185-287$.

- "Gedichte." Herders Werke in funf Bunden. Herausgegeben von Wilhelm Dobbek. 3. Auflage. We1mars Auf'bau Verlag, 1964. I, 1-56.

deutschen Dichtkunst " In The Roment io Thadt Anthology. Herausegegeben von Ronald Taylor. Iondon: Methuen and Co.. 1970. S. 9-25.

Kamenetsky, Christa. "The German Folklore Revival in the 18th Century: Herder's Theory of 'Naturpoesie." Journal of Popular Culture, 6 (Frthling 1973), 836-848.

Klusen, Enst. "Anmexkungen zum Begriff 'Volkslled' und seinem Alter." D1e Musikforschung, 24 (1971), 173-174.

Korff, H. A. Geist der Goethezeit. 4. Auflage. 5 Bunde. Leipzig: Koehler \& Amelang, 1958. 
Krllger, Manfred, "Der menschlich-glttliche Ursprung der Sprache, Bemerkungen zu Herders Sprachtheorle." Wirkendes Wort, 17 (1967). 1-11.

Luther, Martin. "Unber Dolmetschen." In The German Heritage. Herausgegeben von R. H. Phelps. Rev. Ausgabe, New Yorkı Holt, Rinehart \& Winston, 1958. S. 54-55.

Nordsleck, Reinhold. "Herder On the Natural History of Poetry." Tennessee Studies in I1terature, 7 (1962), 1-16.

Opitz. Martin. Buch von der Deutschen Poeterey. Herausgegeben von Richard Alewyn. Tubingen! Max N1emeyer Verlag, 1963.

Schultz, Franz. Klassik und Romantik der Deutschen. 3. Auflage. 2 Bunde. Stuttgart: J. B. Metzlersche Verlagsbuchhandlung, 1959.

Storm, Theodor. Immensee. Herausgegeben von Elmer 0. Wooley. Bostons D. C. Heath \& Co.. 1936.

Wilson, William A. "Herder, Folklore and Romantic Nationallsm," Journal of Popular Culture, 6 (Fruhling 1973), 819-835.

Hiora, Walter. "Das Alter des Begriffes Volkslied." Die Musikforschung, $23(1970), 420-428$. 